\title{
Municipio y mercado en el Aragón moderno: el abasto de carne en Albarracín durante la segunda mitad del Seiscientos*
}

\author{
JOSÉ ANTONIO MATEOS ROYO \\ Universidad de Zaragoza
}

\begin{abstract}
Municipality and Market in Early Modern Aragon: meat supply in Albarracin during the second half of the Seventeenth Century
\end{abstract}

RESUMEN

Estudio relativo a la política desarrollada por el concejo de Albarracín sobre el mercado de carne durante la segunda mitad del siglo XVII. La fuerte orientación ganadera de la zona motivó una modesta intervención pública en el mercado y un mayor grado de autoabastecimiento por parte de la población. El municipio moderó también la presión fiscal sobre la carne para sustentar la demanda local. Debido a la carencia de otras producciones agrarias significativas en la zona, los intereses de la elite local mantuvieron esta concepción del suministro durante el Seiscientos a pesar del creciente endeudamiento municipal. Esta política de abasto urbano favoreció la quiebra municipal. En última instancia, esta debilidad financiera redujo

la protección al consumidor frente a carestías y el control público del mercado en favor de los tratos privados durante la segunda mitad de la centuria.

PALABRAS CLAVE: Municipio / mercado / abasto carne / S. XVII / Albarracin.

\section{ABSTRACT}

This paper studies municipal politics carried out by the Albarracín council concerning the meat market during the second half of the Seventeenth Century. Cattle-raising orientation of the area prompted a slight public intervention on the market and a higher degree of self-provisioning by the inhabitants. Town council also decided to moderate fiscal pressure on the meat transactions in order to support local demand. Due to the lack of other significant agrarian productions in the area, interest of local elites help to maintain this supplying conception during the seventeenth century in spite of raising municipal indebtedness. This policy of town provisioning gradually promoted municipal bankruptcy. Moreover, this financial weakness reduced consumers' protection facing scarcity and public intervention on the market in favour of private transactions during the second half of this century.

KEYWORDS:

Municipality / market / meat supply / 17th Century / Albarracin.

* Este estudio recoge resultados del proyecto «Albarracín en el siglo XVII: municipio, hacienda y mercado», financiado por el Instituto de Estudios Turolenses en el año 2001 dentro del XIX Concurso de Ayudas de Investigación. 
Conocido es el control municipal sobre el suministro de productos básicos ejercido en la España del Antiguo Régimen. Este cometido respondía a una arraigada política de autosuficiencia y protección al consumidor en las autoridades locales, sustentada por el sentir popular y no exenta de temor a alteraciones del orden público en años de carestía. Aspecto poco contemplado por la Historiografía española ${ }^{1}$, los municipios no se atuvieron dentro de este modelo general a un patrón único y estático de suministro durante toda la Edad Moderna. Por el contrario, dentro de un mismo territorio adoptaron distintas soluciones para controlar el mercado local de alimentos básicos en función de la producción del entorno, la capacidad de demanda y las redes comerciales. De acuerdo con estas variables, con una creciente incidencia de las transformaciones acaecidas en los mercados agrarios comarcales y regionales, los concejos introdujeron modificaciones sensibles de la regulación de los intercambios que afectaban en distinto grado a los consumidores y productores de estos artículos. Así, si la expansión demográfica y económica del Quinientos impulsó a los concejos a ampliar el control del mercado de grano existente durante la Edad Media mediante la creación de Pósitos ${ }^{2}$ para sustentar la demanda local de trigo y promover así las actividades comerciales y productivas, la crisis y reestructuración sufrida en la centuria siguiente impondrá una seria remodelación de este sistema de abasto.

Al abordar estas transformaciones del paisaje agrario y las redes comerciales durante la Edad Moderna vinculadas a ciclos económicos, el margen de intervención pública sobre el mercado local vino condicionado tanto en grandes ciudades como en núcleos más modestos por la evolución de las finanzas municipales ${ }^{3}$. Si su solvencia económica posibilitaba promover mediante el aumento del gasto público una política de abastos favorable a la contención de precios y fomento del consumo, la gestación de déficit en su hacienda terminaba por ocasionar un incremento de la fiscalidad que repercutía con especial gravedad en los productos agrarios. El presente estudio recoge toda esta problemática al analizar el abasto

1 En buena parte debido al escaso estudio de la gestión municipal, la distinta incidencia del control público sobre el mercado local y regional de productos agrarios en España durante el Antiguo Régimen ha permanecido ignorada, así como sus repercusiones en la evolución de sus precios. Esta marginación ha sido consolidada por una visión estática de la intervención municipal y el mercado preindustrial por parte de la mayor parte de la Historiografía que ocluye la existencia de serios cambios estructurales del sector agrario durante la Edad Moderna y sus nexos con los acaecidos en Época Contemporánea.

2 Sobre la creación de Pósitos y la regulación del mercado de grano por parte de los poderes públicos en España durante la Edad Moderna, CASTRO, C. de, El pan de Madrid. El abasto de las ciudades españolas del Antiguo Régimen, Madrid, Alianza, 1987, pp. 47-113. La bibliografía utilizada en la obra refleja la concentración de los estudios sobre el tema en las épocas de expansión de la intervención pública sobre las transacciones, como el Quinientos y la segunda mitad del siglo XVIII. Sin embargo, al requerir una reflexión más compleja sobre la remodelación del mercado y el control público derivada de la recesión económica, el tratamiento del Seiscientos ha quedado más relegado.

3 Sobre la evolución de la hacienda municipal en España durante los siglos XVI y XVII, véase BERNABÉ, D., «La fiscalidad de los territorios peninsulares de la Corona de Aragón durante la época de los Austrias», en Fortea, J. I. y Cremades, C. M., (eds.), Política y hacienda en el Antiguo Régimen, Murcia, Universidad, 1993, pp.15-31; y GutiÉRREz Alonso, A., "Ciudades y monarquía. Las finanzas de los municipios castellanos en los siglos XVI y XVII», en RIBOT, L. A. y RosA, L. de, (eds.): Ciudad y mundo urbano en la Época Moderna, Madrid, Actas, 1997, pp.187-211. 
público de carne efectuado en Albarracín, pequeña ciudad del suroeste aragonés cercana a la frontera castellana, durante la segunda mitad del Seiscientos. En primer lugar, intenta reflejar las características peculiares que podía entrañar la organización del abasto y regulación municipal del mercado de la carne durante la Edad Moderna en zonas caracterizadas por una fuerte especialización ganadera que generaba serios intereses de sus elites rectoras por controlar estas transacciones. En segundo término, busca exponer la incidencia del grave endeudamiento municipal y la remodelación del mercado agrario comarcal y regional característicos del Aragón del Seiscientos en la intervención pública sobre el abasto de carne en Albarracín para medir tanto sus posibles similitudes con las políticas adoptadas por otros concejos como sus consecuencias sobre el suministro de la población y el funcionamiento del mercado local.

\section{MERCADO AGRARIO Y CONTROL PÚBLICO LOCAL EN ARAGÓN DURANTE EL SIGLO XVII: REESTRUCTURACIÓN ECONÓMICA Y CRISIS FINANCIERA MUNICIPAL}

Tónica general en Aragón, la gestión municipal del suministro de alimentos básicos se ve afectada durante el Seiscientos por serias transformaciones ligadas al progresivo declive y reestructuración de la economía del reino. Si ya a fines del siglo XVI se perciben síntomas de estancamiento, la expulsión de los moriscos en 1610 añadió una sangría poblacional y un serio golpe al mecanismo de detracción señorial laico que repercutió en toda la economía y dañó en especial al sistema financiero ${ }^{4}$. El continuo declive de la producción industrial y artesanal, muy marcado en la segunda mitad de la centuria, se vio precipitado por la retracción del capital mercantil aragonés a fines del siglo XVI y principios del XVII ${ }^{5}$. Ejercido el control de las principales transacciones en el reino por comerciantes genoveses en 15801620 y franceses a partir de esta última fecha, la recuperación de la burguesía mercantil aragonesa en la segunda mitad de la centuria no excluye la presencia de mercaderes franceses y muestra una orientación más rentista y menos comercial ${ }^{6}$.

4 SALAS, J.A., «La evolución demográfica aragonesa en los siglos XVI y XVII», en NADAL, J. (ed.), La evolución demográfica bajo los Austrias, Alicante, Instituto Juan Gil Albert, 1991, pp.171-175. Sobre la incidencia de la expulsión de los moriscos en Aragón, ABADíA, A., La enajenación de rentas señoriales en el reino de Aragón, Zaragoza, Institución Fernando el Católico, 1998.

5 Redondo, G., Las corporaciones de artesanos de Zaragoza en el siglo XVII, Zaragoza, Institución Fernando el Católico, 1982; PEIRÓ, A., «Comercio de trigo y desindustrialización: las relaciones económicas entre Aragón y Cataluña», en Las relaciones económicas entre Aragón y Cataluña (siglos XVIII$X X)$, Huesca, Instituto de Estudios Altoaragoneses, 1990, pp.41-51; y del mismo autor, Tiempo de industria. Las tierras altas turolenses, de la riqueza a la despoblación, Zaragoza, Centro de Estudios para la Despoblación y Desarrollo de Áreas Rurales, 2002, pp.31-41.

6 Gómez ZorRaquINo, J.I., La burguesía mercantil en el Aragón de los siglos XVI y XVII, Zaragoza, Diputación General de Aragón, 1987; y del mismo, Zaragoza y el capital comercial. La burguesía mercantil en el Aragón de la segunda mitad del siglo XVII, Zaragoza, Ayuntamiento, 1987. Muestra de su orientación más rentista, la adquisición de tierras a nobles endeudados, la compra y arriendo de inmuebles y los préstamos a la monarquía ganaron terreno entre las actividades de la burguesía mercantil zaragozana desarrolladas durante la segunda mitad del siglo XVII. 
Si bien contribuyó a agilizar los intercambios por su mejor adaptación de su valor intrínseco a la cotización del oro y la plata, la llegada de piezas forasteras, falsas o adulteradas con inferior peso y ley que las acuñaciones nativas legales de plata y vellón ${ }^{7}$ aumentó la desconfianza hacia el valor nominal de la moneda, dificultó la conversión entre unidades aragonesas y foráneas en las transacciones y promovió en ocasiones la inflación de precios ${ }^{8}$. La mayor presión fiscal desplegada por la monarquía y las instituciones públicas aragonesas, que recayó con fuerza sobre los productos agrarios, contribuyó a desajustar y remodelar los mercados ${ }^{9}$.

Unido a estos factores, si bien estudios recientes han moderado las pérdidas globales sufridas en el Seiscientos ${ }^{10}$, resulta evidente el estancamiento demográfico de Aragón ante la lenta recuperación vivida tras las fuertes acometidas de la peste bubónica en 1651-54 que sólo se consolidó en sus décadas finales. Perceptible en el claro descenso de su precio desde mediados de siglo ${ }^{11}$, los cereales y otros productos agrarios sufrieron una contracción en su demanda interna que facilitó la remodelación de la economía del reino, en especial su mayor extroversión durante la segunda mitad de la centuria. Propiciada por la irrupción de capital mercantil extranjero y la creciente demanda de materias primas por otros territorios, tras afianzar sus ventajas comparativas, la producción agropecuaria aragonesa se vio impelida así a una mayor orientación exportadora hacia Fran-

7 Asso, I. de: Historia de la Economía Política en Aragón, Zaragoza, Imprenta de Francisco Magallón, 1798 (edición facsímil, Zaragoza, Guara, 1983) pp.279-283. Sobre el tema, MATEU, F., «El sistema monetario en Aragón. Síntesis histórica», en La moneda aragonesa, Zaragoza, Institución Fernando el Católico, 1983, pp.123-127 y REDONDO, G., «Numismática aragonesa en la Edad Moderna» en La moneda ..., pp. 209-213.

8 Así se ha constatado en el precio de los productos artesanales durante las décadas centrales del Seiscientos. Véase MATEOS, J.A.: Auge y decadencia de un municipio aragonés: el concejo de Daroca en los siglos XVI y XVII, Daroca, Centro de Estudios Darocenses, 1997, pp. 410-419. Las disputas entre el concejo y los gremios de Zaragoza por el encarecimiento de las manufacturas durante esta centuria, en REDONDO, G., Las corporaciones... y SAN VICENTE, J.A., Documentos para una historia social y económica del trabajo en Zaragoza (siglos XV-XVIII), Zaragoza, Real Sociedad Económica Aragonesa de Amigos del País, 1988 (2 vols).

${ }^{9}$ Los nexos existentes entre la evolución de la hacienda municipal y del mercado agrario en Aragón durante la época foral moderna, en MATEOS, J.A., «Propios, arbitrios y comunales: la hacienda municipal en el reino de Aragón durante los siglos XVI y XVII», Revista de Historia Económica, 21/1, (2003), pp.6768; y «Control público, hacienda municipal y mercado agrario en el reino de Aragón durante los siglos XVI y XVII», Hispania, (en prensa). Sobre el incremento de la presión fiscal de la monarquía en Aragón durante el Seiscientos, Solano, E., Poder monárquico y Estado pactista (1929-1652). Los aragoneses ante la Unión de Armas, Zaragoza, Institución Fernando el Católico, 1987 y SAnz, P. Política, hacienda y milicia en el Aragón de los últimos Austrias, ente 1640 y 1680, Zaragoza, Institución Fernando el Católico, 1997.

10 SALAS, J.A., «La población aragonesa a comienzos del siglo XVIII», en FERRER, J.A. (dir.), El conde de Aranda y su tiempo, Zaragoza, Institución Fernando el Católico, 2000, vol. I, pp. 355-372. Sobre la epidemia de peste bubónica padecida en Aragón entre 1648 y 1654, MAISO, J., La peste aragonesa de 1648 a 1654, Zaragoza, Universidad, 1982.

11 Sobre la evolución de los precios de los productos agrarios en Europa durante la segunda mitad del Seiscientos, MaRTín AceÑA, P., «Los precios en Europa durante los siglos XVI y XVII: estudio comparativo", Revista de Historia Económica, X, 3, (1992), pp. 359-395. Este mismo proceso se constata para España en HAMILTON, E.J., Guerra y precios en España, 1651-1800, Madrid, Alianza, 1988, pp.147169. Sobre Aragón, véase las series de precios de productos agrarios pertenecientes a distintas localidades expuestas en MATEOS, J.A., «Control público...». 
cia, Valencia y en especial Cataluña, con un marcado peso de la lana y los cereales $^{12}$.

Junto a esta extroversión creciente de la economía, agudizada por la misma presión fiscal municipal, la contracción de la demanda interna impulsó una fuerte reestructuración de la producción agraria local y comarcal en Aragón durante el Seiscientos, mayor de la reconocida para el área mediterránea española ${ }^{13}$. Como refleja la evolución de los diezmos percibidos en la villa de Ejea y los obispados de Huesca y Teruel durante el Seiscientos, ${ }^{14}$ se inició con el descenso de la producción agrícola en Aragón durante la primera mitad de siglo, con especial énfasis en los cereales. Su lenta recuperación durante la segunda mitad de la centuria, ya iniciada en 1660 en Teruel y demorada en Ejea y Huesca hasta sus dos décadas finales, permitió remodelar la producción agraria. La reestructuración agrícola vino propiciada por una mayor especialización productiva que, pese a la protección municipal sobre los excedentes locales, destacó en artículos de fácil comercialización como el vino o el aceite. Detectada a fines del siglo XVI ó principios del XVII, esta especialización local o comarcal creció en la segunda mitad del Seiscientos hasta convertirse sus precios de mercado en referencia en años de carestía para las ciudades próximas, incluida Zaragoza ${ }^{15}$. La remodelación de la ganadería generó cierto aumento de usos ganaderos estantes en zonas de especial aptitud como el sur aragonés — comarcas de Albarracín, Teruel, Daroca y Alcañiz-, sobre todo en núcleos carentes de producciones agrícolas competitivas o donde éstas no se habían consolidado aún ${ }^{16}$. Este proceso, que ahorraba mano de obra, incluyó la conversión de las tierras cultivadas menos fértiles en pastos, la creación de nuevas dehesas municipales y la fundación de algunas

12 Redondo, G., «Las relaciones comerciales Aragón-Francia en la Edad Moderna: datos para su estudio en el siglo XVII», Estudios, 85-86, (1985) pp. 123-154; PEIRÓ, A. «Comercio de trigo...», pp. 35-63; y ToRRAS, J., «La economía aragonesa en la transición al capitalismo. Un ensayo», en Tres estudios de Historia económica de Aragón, Zaragoza, Universidad, 1982, pp. 9-32; y «Relaciones económicas entre Aragón y Cataluña antes del ferrocarril», en Las relaciones económicas entre Aragón y Cataluña (siglos XVIII-XX), Huesca, Instituto de Estudios Altoaragoneses, 1990, pp.17-31.

13 Marcos Martin, A., España en los siglos XVI, XVII y XVIII. Economía y Sociedad, Barcelona, Crítica, 2000, pp. 492-495.

14 Moreno Almarcegul, A., «Población y producción agrícola en el Norte aragonés (1598-1820)», en Congreso de historia rural (siglos XV-XIX), Madrid, Universidad Complutense, 1984, p. 490; y LATORRE, J.M., «La producción agraria en el obispado de Huesca (siglos XVI-XVII)», Jerónimo Zurita, 59-60, (1991), pp. 131-146; y «La producción agraria en el sur de Aragón (1660-1827)» (inédito).

15 Para la limitada especialización agrícola desarrollada en el área mediterránea durante el siglo XVII, Marcos Martín, A., España en ..., pp. 487-491.

16 Una posible reducción de la cabaña ganadera explicaría el aumento de estos usos estantes en el sur aragonés durante el Seiscientos y el descenso de la trashumancia desde Teruel al reino de Valencia durante los dos últimos tercios del siglo XVII defendido en CASTÁN, J.L., Pastores turolenses. Historia de la trashumancia aragonesa en el reino de Valencia durante la época foral moderna, Zaragoza, Centro de Estudios para la Despoblación y Desarrollo de Áreas Rurales, 2002, pp.353-364. Este proceso no debilitó el predominio del trigo — superior a un 70\%- ni la caída de la cebada frente al centeno en los diezmos del cereal cobrados en el obispado de Teruel durante la segunda mitad del siglo XVII. Los cereales inferiores, sobre todo la cebada, están mejor representados en los diezmos percibidos en Huesca y otros lugares anexos durante el Seiscientos. Véase la nota 14. 
asociaciones de ganaderos, sobre todo desde mediados de siglo ${ }^{17}$. La posibilidad de exportar la lana a los Países Bajos y Francia, máxime ante el serio retroceso de la industria textil autóctona, unida a la de comercializar la carne en Cataluña, Valencia o Zaragoza volvió atractiva la propiedad de reses como actividad complementaria para la burguesía mercantil de la capital aragonesa durante la segunda mitad de la centuria ${ }^{18}$.

Toda esta reestructuración del mercado agrario aragonés afectó durante el siglo XVII en mayor medida al mercado público local al coincidir con una progresiva debilidad de la hacienda municipal. La incapacidad de allegar ingresos suficientes para afrontar el déficit generado ya durante la segunda mitad del Quinientos continuó en la centuria siguiente hasta volver insuficiente el perpetuo recurso a la contratación de censales e imponer a los concejos desde fines del siglo XVI la firma de concordias con sus acreedores para demorar pagos o reducir la tasa de interés y poder afrontar sus deudas ${ }^{19}$. Pautada por la mediación de la monarquía y las Cortes aragonesas a raíz de la fuerte erosión de los concejos de señorío derivada del exilio morisco, la firma de concordias se generalizó a lo largo del siglo XVII para consagrar, junto al palpable descenso de la tasa de interés sobre estos préstamos, el progresivo control de los censalistas sobre los propios municipales. Al tiempo, la deuda censal municipal fue transmitida mediante ventas y legados por la oligarquía ciudadana al clero, mejor dispuesto a aceptar una rebaja del interés. Ante la bancarrota final de las haciendas municipales, los censalistas se incautaron de los bienes de propios y los concejos afrontaron como institución una grave pérdida de poder político y económico en el ámbito local en beneficio de sus acreedores, en especial del clero. Confiada la administración municipal a conservadores designados por éstos, su gestión orientada a asegurar el sufragio de pensiones y la luición de censales no saneó unas haciendas concejiles que reflejan una clara debilidad en la primera mitad del Setecientos. Esta situación propició frecuentes discusiones entre oligarquía municipal y censalistas sobre la gestión de propios, la explotación de los comunales o el control del mercado que forzaron la intervención de la monarquía borbónica durante el siglo XVIII.

Este declive municipal, unido a la mayor presión fiscal de la monarquía en 1628-52, obligó a los concejos aragoneses a redefinir tanto la fiscalidad local como su control del mercado de abastos. Introdujeron así nuevos impuestos: dispusieron derramas entre los vecinos para financiar reformas urbanísticas o la in-

17 Mateos, J.A., Auge y decadencia..., pp. 423-424; Archivo Municipal de Alcañiz, Protocolos Notariales, José Peralta, 1667, 28 de diciembre, fol. 3r-13v y 1673-74, 1 de noviembre de 1673, fol.144v-149v y Archivo Municipal de Albarracín (AMA), Concejo, doc. 67, Libro de acuerdos, concordias y mojonaciones del concejo de Albarracín, 1552-1704, fol. 44r-46v, doc. 87 y doc.141.

18 Gómez ZorRaquino, J.I., Zaragoza... pp. 85-86, 161-162.

19 Sobre la gestación del endeudamiento municipal en Aragón durante la época foral moderna y la negociación de su pago con los censalistas, MATEOS, J.A., «Propios, arbitrios...», pp. 62-72; y SALAS, J.A., «Las haciendas concejiles aragonesas en los siglos XVI y XVII. De la euforia a la quiebra», en Poder político e instituciones en la España Moderna, Alicante, Instituto Juan Gil Albert, 1992, pp.11-66. 
cipiente asistencia médica estable y crearon «arbitrios» 20 bajo la forma de monopolios sobre mercancías tales como la nieve, el tabaco, los naipes, el aguardiente, el jabón, el hierro o el carbón. Con todo, su insuficiencia generó la necesidad de afrontar la deuda censal mediante impuestos directos o indirectos ${ }^{21}$. Más usuales en las pequeñas poblaciones los primeros, bajo la forma de la entrega anual de parte de la producción agraria o cuotas según la hacienda particular, la exención de los estamentos privilegiados y las dificultades para estimar la base imponible entre los vecinos pecheros dificultó su percepción. Los impuestos indirectos suscitaron el interés de las elites ciudadanas por su mayor facilidad de percepción y menor incidencia sobre los grupos sociales más acomodados. Abrigaban dos formas principales: la consecución de una licencia real o papal para cargar sisas «vecinales» sobre alimentos básicos ${ }^{22}$, medida que solía entrañar una negociación con los estamentos privilegiados que culminaba en su exención, o la aplicación de un mayor gravamen sobre los corretajes y monopolios de venta sobre los principales alimentos, en especial sobre el pan y la carne, artículos que permitían una mayor detracción.

Esta segunda vía fue adoptada por muchos concejos aragoneses. Según se ha constatado en distintos núcleos - Barbastro, Daroca, Zaragoza, Albarracín-, con las salvedades impuestas por serias carestías de trigo, la gestión municipal se encaminó desde fines del siglo XVI a drenar dinero desde el Pósito, la Cámara de Aceite y la administración de la carne hacia la caja central para frenar su déficit permanente ${ }^{23}$. Se abandonó así la política aplicada en el Quinientos, en especial

20 Ejemplos de estos arbitrios municipales adoptados en Aragón durante el Seiscientos se hallan en INGLADA, J., Estudio de la estructura socio-económica de Huesca y su comarca en el siglo XVII, Zaragoza, Universidad, 1987 (memoria de licenciatura inédita), pp. 246-248, 257; OTERO, F., La Vila de Fraga al segle XVII, Calaceite, Institut d'Estudis del Baix Cinca, 1994, pp. 44-45; MATEOS, J.A., Auge y decadencia..., pp.130-133; y AMA, Concejo, doc.152.

21 Las discusiones motivadas en Aragón por la adopción de uno u otro sistema de recaudación municipal en el siglo XVII, en MATEOS, J.A., «Propios, arbitrios...», pp. 58-59.

22 Estas sisas se aplicaron tanto para reducir la deuda censal como para sufragar gastos específicos de interés común, como los derivados de la asistencia médica proporcionada por los concejos ante la epidemia de peste bubónica padecida en Aragón entre 1648 y 1654. Sobre el tema, MAIso, J., La peste..., pp.176-180; MAteos, J.A, Auge y decadencia..., pp.143-144; y «Propios, arbitrios...», p. 211, nota 50; Sanz, P., Política, hacienda..., pp.180-182 y 292; y Urzay, J., SAngüESA, A. e IBARRA, I., Calatayud a finales del siglo XVI y principios del XVII (1570-1610). La configuración de una sociedad barroca, Calatayud, Centro de Estudios Bilbilitanos, 2001, pp.142 y 150.

23 SALAS, J.A, La población de Barbastro en los siglos XVI y XVII, Zaragoza, Institución Fernando el Católico, 1981, pp. 82-85; y MATEOS, J.A, Auge y decadencia..., pp.183-186, 293-299 y 313-323; «Municipio y mercado en el Aragón moderno: el abasto de trigo en Zaragoza (siglos XVI y XVII)», Espacio, Tiempo y Forma, IV, 15, (2002), pp. 44-45; «La hacienda municipal de Albarracín en el siglo XVII: crisis, endeudamiento y negociación», Teruel, 88-89, (2000-2002), tomo II, pp.188-190; y «Municipio y mercado en el Aragón moderno: el abasto de carne a Zaragoza (siglos XVI-XVII)», Espacio, Tiempo y Forma, IV, 16, (2003), pp.189 y 199. El aumento de los gravámenes sobre los abastos básicos durante el siglo XVII se aprecia en otros concejos sitos en la Corona de Aragón, como revela el caso de Orihuela en BERNABÉ, D., Hacienda y mercado urbano en la Orihuela foral moderna, Alicante, Instituto de cultura Juan Gil Albert, 1989, pp.128-129. Esta mayor presión fiscal se dejó también sentir con fuerza en los municipios castellanos, como demuestran GutiérRez Alonso, A., Estudio sobre la decadencia de Castilla. La ciudad de Valladolid en el siglo XVII, Valladolid, Universidad, 1989, pp. 373-374; MARTínEZ RuIZ, J.I., Finanzas municipales y crédito público en la España moderna. La hacienda de la ciudad de Sevilla, 1528-1768, Sevilla, 
desde mediados de siglo, dedicada en aumentar el gasto público para sostener la demanda y el consumo local al contener la inflación de precios de los alimentos básicos. El encarecimiento de todos estos productos no sólo redujo el control municipal sobre los intercambios al fomentar tratos privados, sino que perjudicó al consumidor en un período de claro declive económico y acentuó la importancia de la labor asistencial practicada por los Hospitales y otras instituciones caritativas. Tras reconocer su menor capacidad de regulación, con especial énfasis en las transacciones de grano, muchos concejos o bien arrendaron a particulares o fomentaron entre la población ciertas responsabilidades de abasto del mercado local bajo su supervisión ${ }^{24}$.

Pauta general, las elites urbanas adaptaron mejor estas contribuciones sobre los productos agrarios a su comercialización dentro y fuera de Aragón conforme se afianzó la reestructuración de la economía en la segunda mitad del siglo XVII25. Artículos con una mayor proyección comercial exterior —carne, trigo— desde mediados de siglo vieron sancionada la fuerte presión fiscal ya aplicada con anterioridad. Menos integrados en los propios municipales, los cánones más modestos sobre el vino y aceite parecen ligados a estrategias de defensa de la producción local tras caer la demanda interna y crecer la competencia del mercado regional. Frente a los intereses de las elites municipales, la oposición de grupos privilegiados y sectores humildes a estos impuestos modificó según su grado de éxito el control público del mercado, la evolución de la presión fiscal y la capacidad de consumo de la población.

\section{ALBARRACÍN EN EL SEISCIENTOS: HACIENDA MUNICIPAL Y MERCADO LOCAL.}

Las líneas generales del declive comentado de la economía aragonesa se aprecian con claridad en Albarracín. Al igual que en todo el sur del reino, la carencia de monedas de plata y vellón aragonesas favoreció la continua introducción de piezas valencianas de menor peso y ley durante el Seiscientos, más adaptadas a la demanda de mercado. Prohibido su uso ya en 1623 por el concejo, éste se acabó imponiendo en Albarracín desde mediados de siglo gracias a los fuertes intercambios comerciales con el reino de Valencia ${ }^{26}$. Sobre todo durante la segunda

\footnotetext{
Ayuntamiento, 1992, p. 310; y Bernardos, J.U., No sólo de pan. Ganadería, abastecimiento y consumo de carne en Madrid (1450-1805), Madrid, Universidad Autónoma, 1997 (tesis doctoral inédita), p.442.

${ }^{24}$ Otero, F., La Vila ..., pp. 35-36; SalAS, J.A., La población..., pp. 97, 102-103; y MateOS, J.A., Auge y decadencia..., p. 297; y «Municipio .... el abasto de trigo...», p. 49.

${ }^{25}$ MATEOS, J.A., "Control público...». Sobre la creciente extroversión de la economía aragonesa en las décadas finales del siglo XVII, véase la nota 12.

${ }^{26}$ AMA, Concejo, doc. 141, libro de contabilidad de 1622-23 y doc.146. Sobre la penetración de moneda valenciana en el sur de Aragón durante el siglo XVII, REDONDO, G., «Numismática...» pp. 210-211 y Archivo de la Corona de Aragón, Consejo de Aragón, legajos 91 y 1369, n.16/1 y 2. Si bien no contempla lo suficiente los intercambios con Teruel en esta centuria, resulta esclarecedor el análisis de las actividades comerciales valencianas y sus incidencias sobre la circulación monetaria realizado por CASEY, J., El reino de Valencia en el siglo XVII, Madrid, Siglo XXI, 1983, pp. 81-103.
} 
mitad de la centuria, la producción textil local retrocedió ante la dura competencia de los paños franceses. La carencia de materia prima suficiente y de calidad al adquirir comerciantes extranjeros la lana producida en la sierra de Albarracín para su exportación a Francia y Holanda forzó a los artesanos locales a adquirir lana castellana más basta para sus tejidos ${ }^{27}$. Tras la carestía de 1652, el municipio pidió así a la Real Audiencia de Aragón que no se incautase los bienes de ciertos pelaires endeudados. Todas las instituciones de la ciudad justificaron ante la Diputación en 1666 a algunos de estos artesanos acusados de pasar paños de contrabando a Castilla por su extrema pobreza, que les forzaba a contraer préstamos con los tejedores para adquirir lana. En 1693 los pelaires solicitaron sin éxito que se les redujese el impuesto aduanero por los paños que extraían fuera del reino desde el $5 \%$ al 3,5\% para remediar su situación económica.

Gráfico 1

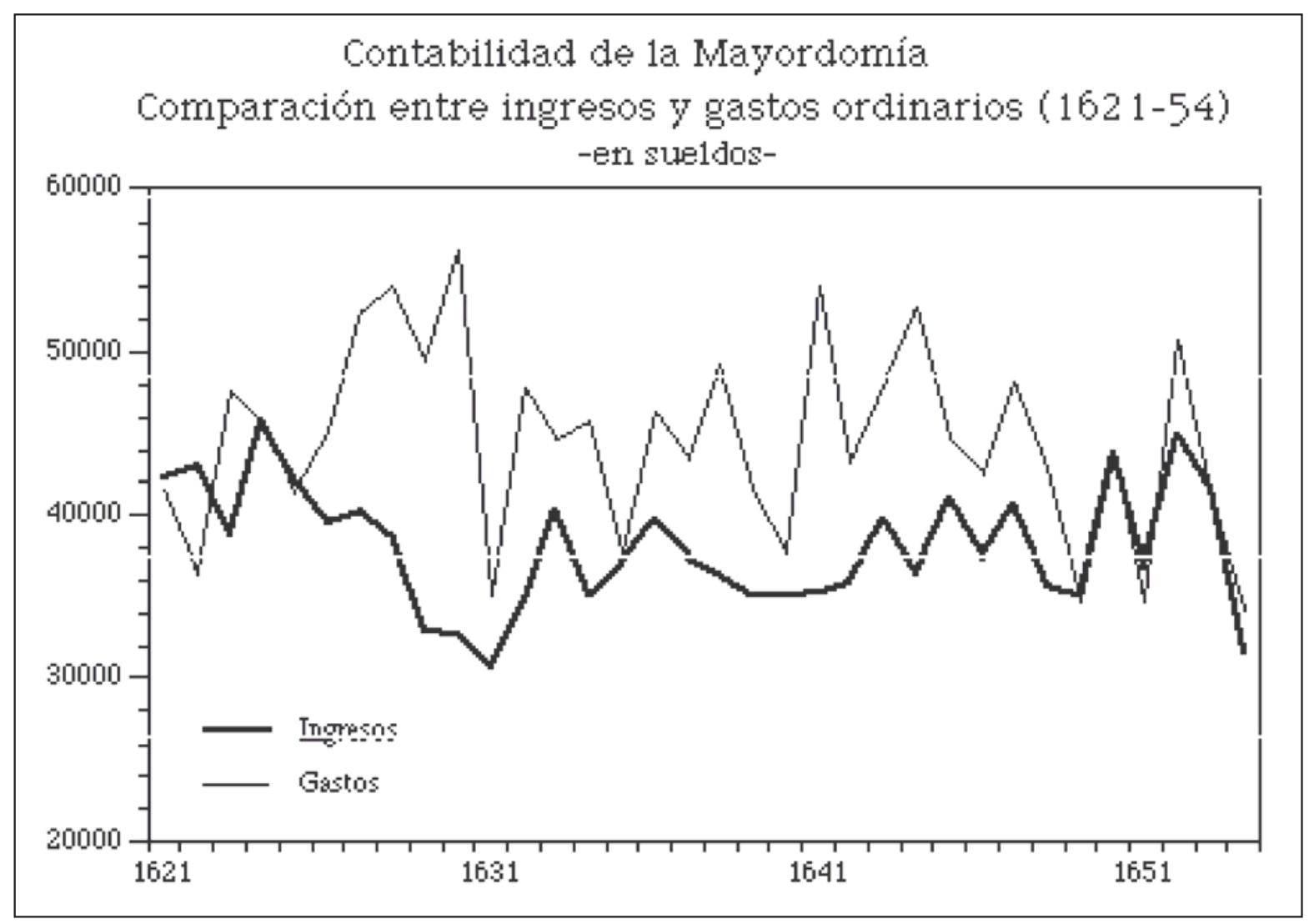

Fuente: AMA, Concejo, doc.141.

Según revela el gráfico 1, la evolución seguida por la hacienda municipal de Albarracín no escapó tampoco a la tónica general descrita para el Seiscientos ${ }^{28}$. El estudio de la gestión practicada por la Mayordomía o caja central municipal entre 1621

27 AMA, doc. 141, libro de contabilidad de 1651-52; CoLAS, G., «Las ciudades y la industria en el reino de Aragón en los primeros años del reinado de Carlos II según diez cartas responsivas», Estudios, 74, (1974), pp.121-128; y Peiró, A., Tiempo de industria..., pp.161-165.

28 Para más detalles sobre esta evolución, MATEOS, J.A., «La hacienda municipal...», pp.171-212. 
y 1654 registra así un serio desajuste entre los ingresos y gastos globales. Esta disparidad tuvo su origen en la clara insuficiencia de los ingresos ordinarios, generados por los propios y arbitrios del concejo, para satisfacer los gastos ordinarios: salarios, pensiones de censales y gastos diversos —administrar justicia, costear fiestas y ceremoniales, mantener propios y comunales o practicar reformas urbanísticas, etcDada la moderación de los salarios y el reducido monto de los gastos diversos, absorbidos en buena parte por las aldeas de la Comunidad debido a un reparto favorable a la ciudad de los costes comunes, el fuerte inmovilismo en los ingresos ordinarios se presenta como el principal responsable de este desfase. El significativo retraso respecto de otros concejos aragoneses en la introducción de nuevos arbitrios anuló las ventajas de Albarracín derivadas de su condición como cabeza de la Comunidad y situará a la Mayordomía en una situación de constante déficit.

Resultado de este proceso, si bien la presión fiscal municipal aplicada en Albarracín fue más moderada que en otras poblaciones aragonesas ${ }^{29}$ durante toda la primera mitad del siglo XVII, la creciente debilidad financiera del concejo resintió su control sobre el mercado local. De especial importancia en alimentos básicos, la existencia de un monopolio municipal parcial o total sobre la venta al por menor facilitaba la regulación del mercado, incluso sobre artículos de escaso arraigo en toda la comarca como el vino. En contraste, la nula producción local y comarcal de aceite por razones climáticas se vio agravada por la carencia de una Cámara municipal destinada a su suministro - como las fundadas en Huesca, Calatayud y Daroca durante el siglo XVI—o la imposibilidad de configurar un monopolio estable susceptible de arriendo. En consecuencia, el abasto de aceite dependía en Albarracín de los arrieros. Debido a la carencia de medios de intervención adecuados, ni siquiera en años de escasez el concejo consideró adquirir este producto para venderlo a la población a un precio módico. Se limitó así a ofrecer modestas compensaciones a estos mercaderes para que moderasen su precio de venta en el mercado público ${ }^{30}$.

29 Véase las notas 20, 21, 22 y 23.

${ }^{30}$ Como ejemplo, AMA, Concejo, doc.141, libro de contabilidad del año 1624-25. 
Gráfico 2

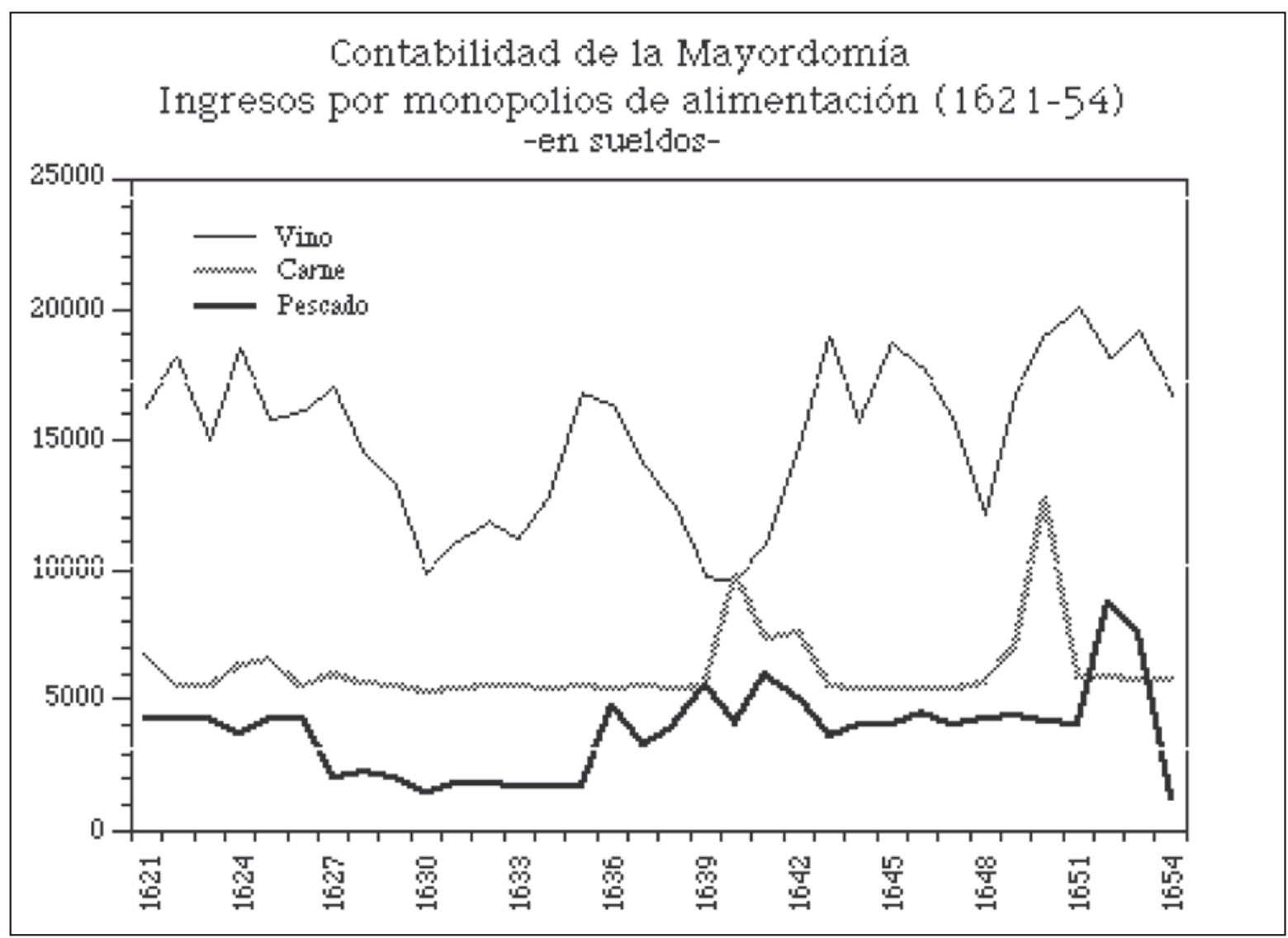

Fuente: AMA, Concejo, doc.141.

Regulado el mercado local de grano por el Pósito creado por el concejo ya en la segunda mitad del Quinientos, los restantes abastos esenciales (vino, carne, pescado) eran controlados por monopolios municipales de venta con un diverso grado de presión fiscal. Según demuestra la contabilidad de la Mayordomía conservada para el período 1621-54 —véase el gráfico 2-, los mayores beneficios eran aportados al municipio por la taberna: un $60,35 \%$ de media del total generado por los tres monopolios. Sometido el vino en los municipios aragoneses por lo común a corretaje, la conformación de este monopolio en Albarracín resulta excepcional. Sus razones se hallan en la casi absoluta carencia de este producto en las Comunidades de Teruel y Albarracín por razones climáticas, así como en el privilegio real concedido a ambas instituciones que las eximía de pagar derechos aduaneros en las fronteras al importar vino desde Valencia ${ }^{31}$. El alto rendimiento del monopolio gracias a esta circunstancia explica el interés de la ciudad por defender en 1628 el privilegio de exención ya ratificado por las Cortes aragonesas de 1626 mediante requerimientos ante la corte del Justicia de Aragón al empezar a

${ }^{31}$ Los síndicos enviados por el concejo de Albarracín ya citaban en las Cortes aragonesas de 1533 al reino de Valencia como zona proveedora de vino, aceite y legumbres, productos deficitarios en el sur aragonés. Véase AMA, Concejo, doc.1, Cartulario de Privilegios, (siglos XIII-XVII), fol. 78-79. 
pagarse el servicio al monarca votado en esta convocatoria, parte del cual era costeado por la Diputación gracias a los aranceles percibidos en las aduanas aragonesas mediante el impuesto de las generalidades ${ }^{32}$. En marcado contraste, la tienda que surtía de pescado a la ciudad y el abasto de carne aportaron sólo un $14,63 \%$ y un $24,71 \%$ de los beneficios totales generados por los tres abastos entre 1621 y 1654. Dadas las mayores posibilidades de detracción derivadas de su demanda, el sacrificio financiero municipal en favor del consumo local adquirió particular relevancia en la carne durante este período.

Frente a esta gestión benévola hasta mediados de siglo, su constante déficit impuso al concejo en la segunda mitad del Seiscientos la alternativa entre mantener su creciente endeudamiento o aumentar la presión fiscal. A esta necesidad responde la configuración entre 1655 y 1666 de un estanco conjunto sobre el tabaco, vino blanco y aguardiente destinado a gravar el consumo de artículos considerados superfluos $^{33}$. Este monopolio municipal concedía durante un trienio a su arrendatario el derecho de venta al por menor en la ciudad de aguardiente y vinos claros —blanco, clarete-, si bien éstos últimos podían seguirse ofreciendo al por mayor en el mercado por particulares. Sometidos estos productos al examen del almotazaf $^{34}$ y un jurado, el precio final de venta de vinos y licores venía fijado al sumarse su coste de compra, los portes y un beneficio consentido al arrendatario de dieciséis sueldos por cántaro en el aguardiente y cuatro sueldos en los vinos claros. Si bien la taberna conservó la venta exclusiva de vino tinto, el concejo favoreció que éste y otros arrendatarios de monopolios municipales la surtiesen de caldos con motivo de sus viajes a Valencia al permitirles entrar partidas de vino tinto exentas de los derechos debidos al almotazaf.

En contraste con estos arbitrios, el aumento de la carga fiscal municipal durante el Seiscientos encerraba especial importancia en abastos esenciales como el trigo y la carne, que podían reportar los mayores ingresos. Así, el concejo se vio forzado a remodelar la gestión de la Cámara del Trigo, sobre todo al remitir las ca-

${ }^{32}$ AMA, Concejo, doc. 67, Libro de acuerdos, concordias y mojonaciones del concejo de Albarracín, 1552-1704, fol. 80r-101v. Pese a algunos intentos de derogar la exención aduanera sobre la importación de vino disfrutada por las Comunidades de Teruel y Albarracín efectuados durante las Cortes celebradas en Zaragoza en 1677-78 con el fin de orientar su abasto hacia las ferias de Daroca, dicho privilegio fue mantenido por estas instituciones hasta la supresión de las aduanas aragonesas por Felipe V en 1707. Véase Archivo de la Diputación Provincial de Zaragoza, Manuscrito 734, Registro del Brazo de Caballeros e Hidalgos, Cortes de 1677-78, fol-432-456.

33 AMA, Concejo, doc. 152.

34 Cargo municipal de origen musulmán, el almotazaf o almotacén era un veedor de pesos y medidas en el mercado público cuya retribución solía incluir el cobro de corretajes sobre los intercambios. Para el origen del cargo y su evolución en España, ChalmetA, P., El señor del zoco en España. Edades Media y Moderna, Madrid, Instituto hispano-árabe de cultura, 1973. Según las ordenanzas municipales de 1564, 1580, 1647 y 1678, esta responsabilidad competía en Albarracín durante la segunda mitad del siglo XVI a un oficial de justicia denominado mayordomo con el cometido adicional de fijar con la ayuda de un regidor el precio de las mercancías que entraban en la ciudad. Durante la segunda mitad del Seiscientos ambas funciones eran ya ejercidas por el almotazaf con el asesoramiento del jurado mayor. Véase LATORRE, J.M., (coord..), Estudios históricos sobre la Comunidad de Albarracín, Tramacastilla, Comunidad de Albarracín, 2003, vol. II, pp. 217-219, 260, 265-266, 303-304 y 342-344. 
restías y descender los precios del grano en la segunda mitad de la centuria ${ }^{35}$. Su debilidad financiera consolidó la reducción de las existencias de este Pósito iniciada en la primera mitad del siglo XVII, medida completada con el abasto prioritario a las panaderías para incrementar los beneficios y los repartos de trigo introducidos a fines de la centuria para renovar las reservas y reducir los costes de almacenamiento. Con el fin de paliar el déficit constante de la Mayordomía, la protección del consumidor y el sustento de la demanda de grano practicados en el Quinientos se sacrificaron en aras de una mayor rentabilidad. Esta reforma de la política de abastos conllevó una pérdida de control público sobre el mercado y el fomento de tratos privados. Pese a arbitrar el concejo medidas de intervención más indirecta sobre la distribución de grano, como el nuevo monopolio fijado para el abasto de las panaderías, se configuró un mercado cereal más abierto en la segunda mitad del Seiscientos.

Junto con el trigo, la carne suponía un artículo preferente de gravamen fiscal. A su amplia demanda por parte de la población unía su mayor facilidad de recaudación frente a otros alimentos básicos al haberse conformado su abasto como bien de propios municipal ya desde la Edad Media. Su carácter de contribución indirecta convencía a las elites ciudadanas instaladas en el concejo, deseosas de evitar tributos directos sobre la propiedad particular. Por el contrario, la imposición de mayores gravámenes sobre la carne levantaba serias suspicacias en los estamentos privilegiados - en especial, entre el clero- por considerarlos una sisa encubierta contraria a la normativa foral que debía ser derogada o aplicarse en exclusiva a los pecheros. Pese a esta oposición, muchos concejos aragoneses aumentaron la presión fiscal sobre la carne ${ }^{36}$, medida que generó un recrudecimiento de la defraudación en el mercado y un descenso del consumo de carne durante la segunda mitad del siglo XVII debido al mayor empobrecimiento de la población. Los siguientes apartados valorarán las decisiones adoptadas por el concejo de Albarracín en este período de acuerdo con las estructuras políticas, sociales y económicas de este núcleo urbano, muy ligadas a la fuerte especialización ganadera de su entorno. Según la información disponible, el primero analiza la gestión habitual del suministro de la carne mediante su arriendo a particulares. El segundo, aquella desarrollada de forma más excepcional mediante la propia administración municipal del abasto.

\section{LA GESTIÓN HABITUAL DEL SUMINISTRO DE CARNE EN ALBARRACIIN: EL SISTEMA DE ARRIENDO (1649-95).}

Como se ha adelantado, la gestión municipal sobre las carnicerías en Albarracín demuestra un gran estatismo durante el período 1621-54 al mantener una baja pre-

35 MATEOS, J.A., «Municipio y mercado en el Aragón moderno: la Cámara de trigo de Albarracín (1650-1710)», Teruel (en prensa).

${ }^{36}$ SALAS, J.A, La población..., pp. 82-85; y MateOS, J.A., Auge y decadencia..., pp.183-186, 293-299 y 313-323; y «Municipio ...: el abasto de carne...», pp.189 y 199. 
sión fiscal sobre la población, en parte ligada al predominio de cierta inercia derivada de las orientaciones favorables al consumidor fijadas en el Quinientos ${ }^{37}$. Sin embargo, la preservación de estos mismos criterios durante la segunda mitad del siglo XVII resulta más sorprendente ${ }^{38}$, dado que el creciente declive financiero del concejo impuso en 1673 negociar con sus acreedores la reducción de la tasa de interés por sus créditos a cambio de introducir nuevos gravámenes ${ }^{39}$. Al centrarse en otros productos, esta mayor presión fiscal no impidió al municipio mantener condiciones atractivas para el arriendo del abasto incluso durante el último cuarto del Seiscientos. Por este motivo, el examen de la contabilidad ${ }^{40}$ correspondiente a la Mayordomía y la administración de las carnes muestran que el concejo de Albarracín asumió en muy contadas ocasiones su gestión directa entre 1621 y 1695.

El arriendo de las carnicerías, sistema denominado en Castilla de «obligados ${ }^{41}$, será el medio preferente de control municipal sobre el mercado local de carne durante la segunda mitad del Seiscientos. Los oficiales de la ciudad tenían prohibida la participación directa o por mediación de otras personas bajo severas penas. Según la norma establecida, los interesados en obtener la gestión de las carnicerías debían concurrir a una puja. Establecida una suma de dinero fija para obtener el usufructo de las carnicerías, así como unos precios iniciales de venta a los que el futuro arrendatario debía vender las carnes de mayor demanda, los aspirantes disponían del tiempo que duraba encendida una vela para realizar ofertas a la baja en los precios de venta de las carnes. En ocasiones, éstos optaban por mantener el precio de venta al público; pero ofrecían al municipio a cambio una suma mayor por el arriendo. La última oferta antes de que se consumiese la vela era la aceptada. Como se solía hacer en los arriendos de mayor importancia, el municipio animaba las pujas al entregar unas compensaciones económicas - denominadas en el siglo XVII ditas o enjantes - por cada nueva oferta realizada con independencia de que fuese la última. Elegido el arrendatario, éste suscribía ante notario con el mayordomo un contrato en que se definían con exactitud las condiciones del arriendo.

Sobre esta base habitual, los contratos conservados para mediados del siglo XVII indican que el concejo de Albarracín fijaba desde el inicio de la subasta el precio de venta para todas las carnes, incluidas aquellas de menor demanda - cordero, oveja, macho cabrío, vaca y buey-y las piezas de menor calidad como las cabezas y vísceras ${ }^{42}$. Los interesados debían centrar sus ofertas a la baja en el

37 AMA, doc. 141.

38 AMA, Concejo, doc.149 y 154.

39 Sobre las líneas de esta negociación, MATEOS, J.A., «La hacienda municipal...», pp. 206-211.

40 AMA, Concejo, doc.141 y 146.

41 Bennassar, B., Valladolid en el siglo de Oro. Una ciudad y su entorno agrario en el siglo XVI, VaIladolid, Ayuntamiento, 1989, pp. 72-73; GutiérRez Alonso, A., Estudio sobre ..., pp. 253-260; CHAcón, F., Murcia en la centuria del Quinientos, Murcia, Universidad-Academia Alfonso X el Sabio, 1979, pp. 365367; Ringrose, D.R., Madrid y la economía española, 1560-1850, Madrid, Alianza, 1980, pp.194-197; MARTínez Ruiz, J.I., Finanzas municipales..., pp. 89-93; y MonTEMAYoR, J., Tolède entre fortune et déclin (1530-1640), Panazol, Presses Universitaires de Limoges, 1996, pp. 78-79.

42 AMA, Concejo, doc.149 y 154. 
precio de venta del carnero o cordero adulto como res de mayor demanda por la población, con pujas por lo común inferiores a la anterior en un dinero por libra. Además del monto del arriendo, cifrado en el siglo XVII en 3.000 sueldos, el arrendatario debía aportar otras sumas para el mantenimiento de las instalaciones. De forma opcional, podía arrendar al concejo el usufructo de ciertas dehesas para apacentar su ganado: la dehesa del Coscojar por 500 sueldos anuales, el Puerto por 600, el cuarto hondonero de Aguas Amargas por 1.000 sueldos o el cuarto somero por 900 sueldos. La suma de todas estas partidas conformaba el monto final del arriendo con la obligación añadida para su usufructuario de proveer los toros para una corrida, celebrada para la Virgen de Agosto, más 200 sueldos para la confitura obsequiada a los jurados en ese día.

Al margen de los rendimientos generados por el abasto según las condiciones del contrato, el municipio de Albarracín podía decidir la inclusión de impuestos adicionales sobre la carne vendida por el arrendatario con el fin de atender a ciertos gastos. En estos casos, si bien éste cobraba el gravamen, otra persona era encargada de asentar en la romana la carne vendida y los ingresos por la sisa en un libro por separado de la contabilidad de las carnicerías. Este recurso fue utilizado para sufragar servicios a la monarquía y contribuciones de guerra durante el segundo cuarto del siglo XVII, sobre todo durante la guerra de Cataluña al primar el sistema de sisas sobre el de repartos según la condición social y propiedad ${ }^{43}$. Todavía el arriendo suscrito en 1654 expone la posibilidad de aplicar durante el trienio una sisa de dos dineros para pagar sumas adeudadas a la monarquía a cuenta del servicio votado por las Cortes aragonesas en 1646, así como sufragar «otras necesidades de la ciudad» ${ }^{44}$. Si bien pudo utilizarse este recurso de forma ocasional, la evaluación de los ingresos habituales del concejo de Albarracín efectuada en 1673 no menciona sisas específicas ${ }^{45}$ destinadas a cancelar censales o pagar sus intereses anuales, medida que hubiera necesitado la aquiescencia del influyente clero catedralicio.

Adscrito a la elite social de ciudadanos e infanzones ${ }^{46}$, el arrendatario debía presentar como garantía de su buena gestión fianzas o fiadores solventes, que debían ser aprobados por el concejo. Estas fianzas reconocían junto con el arrendatario mediante un documento notarial denominado comanda adeudar al mayordo-

43 AMA, Concejo, doc.141 y 142. Sobre el mayor recurso a las sisas para sufragar ciertos gastos por parte de los concejos aragoneses durante el Seiscientos, véase la nota 22.

44 AMA, Concejo, doc.149.

45 AMA, Concejo, doc.154. Reflejo de esta oposición por parte de los estamentos privilegiados, los impuestos cargados por la taberna a los clérigos de la ciudad les eran restituidos durante el Seiscientos tras estimarse su consumo anual con objeto de evitar que utilizasen su exención tributaria para adquirir vino destinado a particulares laicos. Véase AMA, Concejo, doc.141, 144, 145, 150 y 157.

46 AMA, Concejo, doc.149 y 154. La adscripción del arrendatario a esta elite social resultaba común en los concejos aragoneses durante la Edad Moderna. Véase URZAY, J., SANGÜESA, A. e IBARRA, I., Calatayud a finales ..., p.142; MATEOS, J.A., Auge y decadencia..., pp. 315-319; y «Municipio .... el abasto de carne...», pp.187-188 y 206-207. Como revela el caso de Madrid, también era usual en los municipios castellanos. Véase Bernardos, J.U., No sólo de pan... p. 354. 
mo una elevada cantidad que en realidad no habían recibido, pero que servía a éste como administrador principal de la hacienda municipal para asegurarse el cumplimiento de sus compromisos: el pago del arriendo y la devolución del adelanto en dinero o especie cedido por el concejo al arrendatario al iniciar el abasto más los intereses de un 5\% sobre su monto, fijado en Albarracín en 20.000 sueldos. También permitía al mayordomo garantizar la percepción de posibles indemnizaciones en caso de realizarse malversaciones o una gestión deficiente. Una contracarta solía asegurar al arrendatario y sus fianzas que el monto de la comanda anterior sólo se aplicaría en los casos citados vinculados al abasto de la carne en la ciudad.

Vigente en la mayoría de los arriendos ${ }^{47}$, el recurso a la vistreta permitía resolver dos problemas de importancia. El primero, la necesidad de disponer de importantes sumas de dinero por los arrendatarios del abasto para cumplir con las condiciones dictadas en el arriendo de procurar el suministro por la población a un precio asequible. El segundo, encontrar una salida para los excedentes en especie (reses, tocino, sebo, lana,...) de que disponía cada arrendatario al finalizar el período de arriendo. La solución venía de la mano de la vistreta o préstamo por el municipio de una cantidad de dinero al arrendatario. En esta suma estaba incluida la evaluación por comisarios del valor de las existencias restantes del ejercicio anterior del abasto que el arrendatario entrante recibía del saliente. El municipio aceptaba esta cesión por el arrendatario saliente de los remanentes en concepto de devolución de la vistreta así como las sumas necesarias para completar su monto global, entregadas de inmediato al nuevo arrendatario. En el caso de que el monto de la vistreta se viese superado por el valor de los remanentes en especie acumulados, el arrendatario saliente era compensado en dinero por el entrante. De este modo, el problema de las existencias era solucionado al ser englobadas por un préstamo que el concejo realizaba año tras año basado en la transferencia de una misma cantidad global — parte en especie, parte en dinero- por parte de un arrendatario a su sucesor.

Este arriendo, establecido por uno o - con más frecuencia- tres años, confería el derecho a la venta pública al por menor en Albarracín de buen número de carnes - carnero, cordero, oveja, macho, vaca, buey - con exclusión del tocino, cuyo suministro era arrendado por separado en atención a sus peculiares características impuestas por el autoabastecimiento familiar mediante la crianza y sacrificio anual de un cerdo. A diferencia de otras poblaciones ${ }^{48}$, el arriendo de las carnicerías no permitía a su usufructuario cobrar gravámenes a particulares que vendiesen en el mercado público caza mayor - ciervos, corzos- o bueyes y vacas de su propiedad tras ser sacrificados. Sin embargo, la característica más notoria de la gestión de la carne en Albarracín residía en no erigirse en un monopolio absoluto

47 AMA, Concejo, doc.141, 149 y 154. Aplicado también a otros abastos, este sistema era habitual en otros municipios aragoneses. Véase MAteos, J.A., Auge y decadencia..., pp.154-158.

48 Así sucede en la ciudad de Daroca, según MATEOS, J.A., Auge y decadencia..., p. 311. 
de la venta al por menor ${ }^{49}$. Los contratos estipulaban que los vecinos podían adquirir la carne que necesitasen para su abasto, incluso si ésta era destinada para su salazón y almacenamiento. Sí estaba prohibida la compra de carne en las carnicerías para su reventa, dado que perjudicaba al arrendatario y encarecía su precio en la ciudad. El suministro público convivía así con numerosas transacciones privadas de carne en el mercado local impulsadas por la existencia de muchos pequeños ganaderos con reses disponibles gracias a su acceso a los pastos sitos en la Comunidad de Albarracín. Esta complementariedad entre abasto público y privado se subrayaba al prohibirse adquirir bueyes y vender sus cuartos en la ciudad durante las fechas en que el arrendatario estaba obligado por contrato a ofrecer esta res en las carnicerías. Unida a la baja presión fiscal aplicada, al permitir un elevado margen de suministro a la población, este monopolio relativo de venta parece afrontar en Albarracín una menor oposición por parte de los estamentos privilegiados y una defraudación vecinal en el mercado local más tenue de la apreciada en muchos municipios aragoneses y castellanos durante el Seiscientos ${ }^{50}$.

Sobre esta base, las condiciones de arriendo intentaban garantizar a los vecinos de Albarracín las mejores condiciones posibles de calidad, precio y accesibilidad al producto en el suministro de carne ${ }^{51}$. El arrendatario recibía la botiga, la rebotiga y el matadero como principales instalaciones ligadas al abasto, así como contrataba a los cortantes encargados de la venta al público, cuya gestión se sometía a una estricta vigilancia. El almotazaf velaba por la exactitud de las pesas utilizadas y su adecuación con el precio cobrado. A los jurados se les encargaba supervisar la calidad del género, limpieza de las dependencias y licitud del precio de venta. Caso de hallar desabastecidas las carnicerías de cierto producto, los jurados podían realizar a costa del arrendatario las gestiones oportunas hasta obtenerlo. Se procuraba repartir con equidad entre los pobres las vísceras de los animales sacrificados, más asequibles debido a su mayor baratura, a la par que su sangre les era entregada gratis.

Al igual que se ha constatado para otras ciudades ${ }^{52}$, la carne del entonces llamado carnero - hoy cordero adulto-, era continua a lo largo del año al ser la de mayor demanda. Como concesión a las mayores dificultades de abasto, entre Navidad y Pascua Florida se le permitía adquirir carne de inferior calidad, como la procedente del río Cella, y se limitaba la venta de carnero a uno por día entre esta última fecha y San Juan Bautista. Por el contrario, los deberes del arrendatario eran más matizados en el suministro de otras carnes. Sólo debía garantizar la ven-

49 AMA, Concejo, doc. 149.

50 Esta tendencia se aprecia con claridad en Aragón, sobre todo en la segunda mitad del siglo XVII. Véase SALAS, J.A., La población..., pp. 84-85; y MATEOS, J.A., Auge y decadencia..., pp. 320-321; y «Municipio .... el abasto de carne...», pp. 210-212. Para Castilla, GutiéRREZ Alonso, A., Estudio sobre ..., pp. 263-265; y BeRnaRdos, J.U., No sólo de pan... p. 442.

51 AMA, Concejo, doc.149. Sobre el cargo de almotazaf, véase la nota 34.

52 Véase SALAS, J.A., La población..., pp. 86-88; y MATEOS, J.A., Auge y decadencia... pp. 312-313; y «Municipio ...: el abasto de carne...», p. 213. 
ta de una o dos reses de vacuno cada sábado entre San Juan y San Miguel de Septiembre. La oferta de cordero -el ternasco actual— únicamente se ejercía entre el 20 de junio y el 20 de julio, la de oveja desde el día 15 de julio hasta Nuestra Señora de Agosto y la de macho cabrío entre la fiesta de Todos los Santos y Carnestolendas. El reducido tiempo concedido para la venta de corderos y ovejas en Albarracín, inferior al apreciado en otras poblaciones, habla bien a las claras del papel desempeñado en el abasto de la ciudad por la importante cabaña disponible de estas reses en la Comunidad de aldeas ${ }^{53}$.

Para cumplir con su cometido, el arrendatario debía procurarse una cabaña ganadera suficiente. Esta le venía ofrecida en parte por las reses sobrantes del arriendo o la administración anterior, que le eran entregadas mediante la vistreta. Su mantenimiento se veía favorecido al incluir en el arriendo el disfrute de ciertos derechos de pasto; pero tenía prohibido el acceso a la dehesa destinada a los vecinos de la ciudad ${ }^{54}$. El arrendatario podía sin ningún coste adicional llevar a pacer 450 cabezas de ganado lanar y otras 50 de cabrío en la Losilla, Portichuelo, Carrascalejo, Cerrolaorca y Viñamonte. En estas dehesas y sus solanas, distribuidas de forma que el número del ganado apacentado por la noche doblase al del día, las reses destinadas a las carnicerías se alimentaban todo el año excepto entre el 8 de abril y San Miguel de Septiembre. Durante este período, el concejo procedería a arrendar su usufructo a los ganaderos aragoneses o forasteros que subían sus ganados desde el sur hasta las sierras de Albarracín ${ }^{55}$. Sólo en caso de heladas, que reducían los pastos disponibles para el ganado, los vecinos de la ciudad podían apacentar sus ganados durante el otoño e invierno en estas zonas reservadas al gestor del abasto con el consentimiento previo del mayordomo y los jurados de Albarracín.

Junto a estas dehesas confiadas con el abasto, su arrendatario podía contratar con el concejo el usufructo de los pastos sitos en el Coscojar, el Puerto y los cuartos somero y hondonero de Aguas Amargas bajo ciertas condiciones ${ }^{56}$. En las dos primeras dehesas, el arrendatario no podía entrar más de 70 cabezas de ganado

53 La importancia de la actividad ganadera en la Comunidad de aldeas de Albarracín se aprecia con claridad en los contados censos de reses disponibles para la Edad Moderna en Aragón. Los más cercanos a la época estudiada en este trabajo — segunda mitad del Seiscientos - se documentan en 1699, aportado por la Casa de ganaderos de Zaragoza y 1713, solicitado por el Consejo de Aragón y elaborado mediante cálculos a partir del impuesto de la sal. Véase Archivo de la Casa de Ganaderos de Zaragoza (ACGZ), Caja 260, ligamen 142, número 13 y Archivo Histórico Nacional (AHN), número 6810, apartados 73 y 74. Los datos de este último censo han permitido realizar un estudio de la distribución de la propiedad ganadera en la Comunidad de aldeas de Albarracín. Véase CASTÁN, J.L., Pastores turolenses..., pp. 201-217; y «La ganadería de Albarracín en la Edad Moderna», en LATORRE, J.M. (coord.), Estudios históricos ..., vol. I, pp. 534-542.

54 AMA, Concejo, doc. 149. La disposición de dehesas y boalares por parte de los gestores de las carnicerías resulta común a muchos municipios aragoneses. Como ejemplos, OTERO, F., La Vila..., p. 43; Mateos, J.A., Auge y decadencia... p. 313; Urzay, J., SangüEsa, A. e IBARRA, I., Calatayud a finales ..., p. 141; y CASTÁn, J.L., Pastores turolenses..., p. 70-71.

55 Sobre la gestión de las dehesas concejiles en la Comunidad de Albarracín y su mayor utilización en la temporada estival, CASTÁN J.L., «La ganadería...», p. 494-496.

56 AMA, Concejo, doc. 149. 
cabrío debido a la degradación que éste producía en el pasto. Con objeto de permitir al monte recuperarse, el pastoreo en el Puerto se hallaba vedado entre el 8 de abril y el 29 de junio, día de San Juan Bautista. Esta prohibición también regía en el Coscojar y se veía extendida hasta San Miguel de Septiembre durante el último año de arriendo incluso si éste era el único. Con motivo de administrar las carnicerías, el concejo amplió los límites de esta dehesa en diciembre de 1649 y aumentó los ingresos obtenidos por su usufructo al firmar en abril de 1650 un nuevo contrato de arriendo del abasto ${ }^{57}$. Según demuestra la contabilidad de la administración del abasto ${ }^{58}$, los cuartos somero y hondonero de Aguas Amargas presentaban mayores ventajas para apacentar las reses que los restantes pastos opcionales y eran zona de pastoreo frecuente para el ganado vinculado a las carnicerías.

\section{LA GESTIÓN EXCEPCIONAL DEL SUMINISTRO DE CARNE EN ALBARRACÍN: LA ADMINISTRACIÓN MUNICIPAL (1649-1695)}

La moderación descrita de los beneficios municipales obtenidos de las carnicerías y la existencia de una amplia cabaña ganadera en la comarca favorecieron en Albarracín el sistema de arriendo durante la mayor parte del Seiscientos. Superado el período 1620-50, caracterizado por una mayor presión fiscal de la monarquía y dificultades de abasto que forzó a muchos concejos aragoneses a asumir la gestión de sus carnicerías ${ }^{59}$, el descenso del precio de la carne en la segunda mitad de la centuria consagró el predominio absoluto del arriendo frente a su más habitual alternancia con la administración en muchos otros núcleos durante este período. Fiel reflejo de este carácter excepcional, según revela la contabilidad municipal ${ }^{60}$, las carnicerías fueron sólo administradas siete años entre mediados y fines de esta centuria: 1649, 1650, 1667, 1668, 1669, 1681 y 1695. En su mayoría se vinculan a serios problemas en el abasto de carne en el mercado hasta culminar en la escasez padecida en 1695 en todo el reino: el fallecimiento de buena parte del ganado tras padecerse fuertes heladas impuso a la Diputación prohibir su exportación de Aragón durante cinco años ${ }^{61}$.

Al igual que las restantes administraciones municipales, como la Cámara del Trigo o la Mayordomía, la gestión de las carnicerías se iniciaba en San Miguel de

57 AMA, Concejo, doc. 67, Libro de acuerdos, concordias y mojonaciones del concejo de Albarracín, 1552-1704, fol. 44r-46v.

58 AMA, Concejo, doc.146.

59 Salas, J.A., La población..., pp. 78-82; Otero, F., La Vila ..., pp.148-151 y Mateos, J.A., Auge y decadencia..., pp. 317-318; y «Municipio .... el abasto de carne...», pp. 194-204. El monopolio sobre la venta de carne es administrado también con mayor frecuencia en Castilla por el concejo durante el siglo XVII ante las mayores dificultades de suministro, según reflejan GutiÉRREZ Alonso, A., Estudio sobre ..., pp. 255-258; y MONTEMAYOR, J., Tolède ..., p. 78.

60 AMA, Concejo, doc. 146.

61 Sobre esta carestía, véase ACGZ, Caja 260, ligamen 142, doc. 13; y Archivo Municipal de Zaragoza (AMZ), Actas Municipales, 1695, 10 de marzo, 27 de junio. 
Septiembre para concluir al año siguiente con la rendición de cuentas, pese a que el concejo decidiera que debía proseguir la administración ${ }^{62}$. Caso de prorrogarse, se solía designar otro gestor o mantener al anterior para todo el período, como sucede entre 1667 y 1669. Sólo la seria carestía de 1695 indujo al concejo de Albarracín a nombrar tres administradores al frente de las carnicerías. A semejanza de los gestores del Pósito o la administración principal — cambrero, mayordomo-, el administrador de la carne era escogido por el concejo entre la minoría dirigente de ciudadanos e infanzones que lo componía. Este vínculo social explica que la mayoría de estos administradores -Esteban Zalón, Luis Sánchez Santa Cruz, Juan Francisco Sánchez Moscardón- ejerciesen también como cambreros en la segunda mitad del siglo XVII. Destaca en especial el reiterado nombramiento de Luis Sánchez Santa Cruz y Torres en 1667, 1668, 1669 y 1695 para gestionar las carnicerías de la ciudad. La inclusión de reses de su propiedad en el rebaño municipal enviado en trashumancia hacia el sur durante el año contable de 1667 lo identifican como ganadero, así como revelan una confluencia de intereses públicos y privados también constatada en la administración de la Cámara del Trigo.

Como refleja el cuadro 1, la venta de las distintas carnes en las tablas reportaba la mayoría de los ingresos al administrador del abasto: un 86 '3\% de media para los años $1649,1650,1667,1668,1681$ y 1695 . El 13,7\% restante provenía de recursos adicionales para obtener beneficios, como la venta de pastos, lana y piel $^{63}$. La lana procedente de la esquila del ganado propiedad del concejo durante la primavera revestía especial importancia -un $8,65 \%$ del total de los ingresos - entre estos aprovechamientos, si bien se veía mermada por el pago del diezmo correspondiente al obispado de Albarracín ${ }^{64}$. La venta de la piel de las reses, que solían reportar dos sueldos por carnero, así como su sebo proporcionaban escasos ingresos: un 3,14\% del total. El arriendo de ciertos pastos a ganaderos tras desestimarse su utilización por la cabaña municipal generaba escasas ganancias - un 1,83\% del total-, cuyo monto bruto era siempre inferior al del gasto derivado de comprar el usufructo temporal de zonas de pastoreo más ventajosas para estas reses.

62 AMA, Concejo, doc.146. Sobre las administraciones municipales de Albarracín y el status social de sus gestores durante el Seiscientos, MATEOS, J.A., «La hacienda municipal...» y «Municipio ....: la Cámara de trigo....".

63 Estos aprovechamientos complementarios del abasto de la carne eran muy usuales. Su incidencia sobre los ingresos de las carnicerías se revela semejante en otros concejos aragoneses, como revelan los estudios de SALAS, J.A., La población..., pp. 80-82 y OTERO, F., La Vila ..., p. 43.

64 Para el cobro del diezmo sobre los corderos y la lana en la Comunidad de Albarracín durante la Edad Moderna, CASTÁN, J.L. «La ganadería...», pp. 532-534. La importancia de la venta de lana para los ganaderos de la Comunidad motivó la creación de un monte de lanas en Albarracín durante la segunda mitad del siglo XVII para poder negociar esta mercancía en mejores condiciones con los comerciantes aragoneses y extranjeros. Véase CASTÁN, J.L., Pastores turolenses..., pp. 187-192. 
Cuadro 1. Ingresos de la administración de la carne (1649-95) (en sueldos y dineros)

\begin{tabular}{c|c|c|c|c|c|c}
\hline Años & $\begin{array}{c}\text { Venta } \\
\text { de pastos }\end{array}$ & $\begin{array}{c}\text { Venta } \\
\text { de lana }\end{array}$ & $\begin{array}{c}\text { Venta } \\
\text { de piel }\end{array}$ & $\begin{array}{c}\text { Ventas } \\
\text { de carne }\end{array}$ & $\begin{array}{c}\text { Otros } \\
\text { ingresos }\end{array}$ & $\begin{array}{c}\text { Ingresos } \\
\text { totales }\end{array}$ \\
\hline 1649 & $624 \mathrm{~s} 6 \mathrm{~d}$ & $3.783 \mathrm{~s}$ & $2.487 \mathrm{~s}$ & $54.821 \mathrm{~s} \quad 3 \mathrm{~d}$ & & $61.715 \mathrm{~s} 9 \mathrm{~d}$ \\
1650 & $800 \mathrm{~s}$ & $5.965 \mathrm{~s} 6 \mathrm{~d}$ & $1.300 \mathrm{~s}$ & $53.570 \mathrm{~s}$ & $192 \mathrm{~s}$ & $61.827 \mathrm{~s} 2 \mathrm{~d}$ \\
1667 & $360 \mathrm{~s}$ & $5.253 \mathrm{~s}$ & $1.266 \mathrm{~s}$ & $37.944 \mathrm{~s} \quad 10 \mathrm{~d}$ & & $44.873 \mathrm{~s} 10 \mathrm{~d}$ \\
1668 & $502 \mathrm{~s} 10 \mathrm{~d}$ & $4.417 \mathrm{~s}$ & $1.056 \mathrm{~s}$ & $28.953 \mathrm{~s} \quad 5 \mathrm{~d}$ & & $34.929 \mathrm{~s}$ \\
1669 & $?$ & $?$ & $?$ & $?$ & $?$ & $33.493 \mathrm{~s} 4 \mathrm{~d}$ \\
1681 & $1.296 \mathrm{~s} 8 \mathrm{~d}$ & $1.904 \mathrm{~s}$ & $1.284 \mathrm{~s}$ & $29.761 \mathrm{~s} \quad 11 \mathrm{~d}$ & $20 \mathrm{~s}$ & $34.266 \mathrm{~s} 7 \mathrm{~d}$ \\
1695 & $700 \mathrm{~s}$ & $1.648 \mathrm{~s}$ & (830s) & $23.246 \mathrm{~s} \quad 1 \mathrm{~d}$ & & $26.424 \mathrm{~s}$ \\
\hline
\end{tabular}

$\begin{array}{lll}\text { Fuente: AMA, Concejo, doc.146 } & \text { Abreviaturas: } & \mathrm{s}=\text { sueldo } \\ & \text { Adm. }=\text { Administración } \\ \text { Mayord. = Mayordomía } & \mathrm{d}=\text { dinero }\end{array}$

Cuadro 2. Gastos de la administración de la carne (1649-81) (en sueldos y dineros)

\begin{tabular}{c|c|c|c|c|c|c}
\hline Años & $\begin{array}{c}\text { Compra } \\
\text { de pastos }\end{array}$ & $\begin{array}{c}\text { Compra } \\
\text { de ganado }\end{array}$ & $\begin{array}{c}\text { Costes } \\
\text { de adm. }\end{array}$ & $\begin{array}{c}\text { Gastos } \\
\text { ordinarios }\end{array}$ & $\begin{array}{l}\text { Ganancias } \\
\text { a mayord. }\end{array}$ & \multicolumn{1}{|c}{$\begin{array}{c}\text { Gastos } \\
\text { totales }\end{array}$} \\
\hline 1649 & $1.002 \mathrm{~s} 4 \mathrm{~d}$ & $50.590 \mathrm{~s}$ & $3.321 \mathrm{~s} 2 \mathrm{~d}$ & $54.913 \mathrm{~s} 6 \mathrm{~d}$ & $6.802 \mathrm{~s} 3 \mathrm{~d}$ & $61.715 \mathrm{~s} 9 \mathrm{~d}$ \\
1650 & $1.100 \mathrm{~s}$ & $25.373 \mathrm{~s}$ & $3.018 \mathrm{~s}$ & $29.491 \mathrm{~s}$ & $12.336 \mathrm{~s}$ & $41.827 \mathrm{~s} 2 \mathrm{~d}$ \\
1667 & $1.781 \mathrm{~s} 8 \mathrm{~d}$ & $31.663 \mathrm{~s} 4 \mathrm{~d}$ & $4-239 \mathrm{~s} 6 \mathrm{~d}$ & $37.684 \mathrm{~s} 6 \mathrm{~d}$ & $7.189 \mathrm{~s} 4 \mathrm{~d}$ & $44.873 \mathrm{~s} 10 \mathrm{~d}$ \\
1668 & $2.168 \mathrm{~s} 9 \mathrm{~d}$ & $32.855 \mathrm{~s}$ & $4.183 \mathrm{~s}$ & $39.106 \mathrm{~s} 9 \mathrm{~d}$ & $5.775 \mathrm{~s} 7 \mathrm{~d}$ & $44.882 \mathrm{~s} 4 \mathrm{~d}$ \\
1669 & $?$ & $?$ & $?$ & $24.721 \mathrm{~s} 8 \mathrm{~d}$ & $8.771 \mathrm{~s} 8 \mathrm{~d}$ & $33.493 \mathrm{~s} 4 \mathrm{~d}$ \\
1681 & $1.982 \mathrm{~s} 5 \mathrm{~d}$ & $27.706 \mathrm{~s} 6 \mathrm{~d}$ & $682 \mathrm{~s} 4 \mathrm{~d}$ & $30.371 \mathrm{~s} 3 \mathrm{~d}$ & 0 & $30.371 \mathrm{~s} 3 \mathrm{~d}$ \\
\hline
\end{tabular}

De forma lógica, los principales gastos ordinarios de la administración venían constituidos -véase el cuadro 2- por las compras de reses: un $87,45 \%$ de media para los años 1649, 1650, 1667, 1668 y 1681 . Le seguían en importancia los costes de administración —un 8,1\%, incluido el salario de pastores y esquiladores-más el pago por el usufructo de pastos no pertenecientes al concejo - un 4,45\%-. Una vez definidos ingresos y gastos en la rendición final de cuentas, se decidía la suma transferida a la Mayordomía como ganancia neta municipal, definida por el mayor o menor gravamen aplicado a la venta de las distintas carnes en las tablas. Si la vistreta se entregaba por separado, los ingresos y gastos totales coincidían. Por el contrario, si la vistreta se entregaba en especie de forma parcial -1668, 1681-, los gastos supe- 
raban a los ingresos. En 1650 éstos superaron a los gastos totales en 20.000 sueldos justos al decidirse entregar la vistreta en dinero al nuevo arrendatario.

Pese a su escaso número, la contabilidad conservada refleja con claridad las líneas generales del abasto público de carne practicado en Albarracín durante la segunda mitad del Seiscientos. La modesta oferta de reses proporcionada por la administración - véase el cuadro 3- resulta acorde no sólo con el reducido peso demográfico pese a su condición de ciudad, sino con la abundante cabaña ganadera existente en las Comunidades de Teruel y Albarracín, así como con las facilidades concedidas a la población para surtirse de carne al margen del abasto. Como ya se deducía del escaso período de suministro al año impuesto en los contratos a los arrendatarios del abasto, estas características provocaron que ciertas reses cuya carne era de menor calidad —ovejas, cabras, machos cabríos- disfrutasen de una oferta más escasa y menos constante que la proporcionada por otras administraciones de la carne en distintos municipios de Aragón -Zaragoza, Daroca, Calatayud, Barbastro, Fraga - durante este período ${ }^{65}$. El suministro continuo de carne se ceñía así en Albarracín a asegurar el suministro de carneros y corderos, aparte de algunas vacas.

Cuadro 3 Administración de la carne: ventas de reses (1649-95)

(en unidades)

\begin{tabular}{ccccccc}
\hline Años & Carnero & Cordero & Oveja & Vaca & Buey & Cabrón \\
\hline 1649 & 945 & 180 & 28 & 6 & 2 & 0 \\
1650 & 846 & 90 & 0 & 6 & 0 & 0 \\
1667 & 633 & 227 & 0 & 10 & 0 & 0 \\
1668 & 516 & 110 & 0 & 11 & 0 & 0 \\
1681 & 636 & 232 & 0 & 0 & 0 & 0 \\
1695 & 415 & 90 & 0 & 0 & 0 & 22 \\
\hline
\end{tabular}

Fuente: AMA, Concejo, doc. 146

Común a todo el reino aragonés en la segunda mitad del Seiscientos ${ }^{66}$, la evolución de las ventas - véase el cuadro 3- demuestra consolidar ya en la década de los sesenta un descenso de la demanda de carnero acorde con el paula-

${ }^{65}$ Salas J.A., La población..., pp. 78 y 82-85; Otero, F., La Vila ..., p. 148; URZAY, J., SANGÜESA, A. e IbarRA, I., Calatayud ..., pp. 142-143; y MAteos, J.A., Auge y decadencia... pp. 316-323; y «Municipio .... el abasto de carne...», pp. 200-201 y 212-213.

66 Véase la nota anterior. El descenso de la ración de carne por persona resultó común en toda Europa, con especial nitidez en los países mediterráneos, a partir de 1550 durante toda la Edad Moderna para mantenerse en la Europa del Este hasta bien entrado el siglo XIX. La menor posibilidad de adquirir las carnes de mayor calidad potenciaría el consumo de vaca y tocino salado por parte de los sectores más pobres de la población. Sobre el tema, BRAUDEL, F., Civilización material, economía y capitalismo, siglos XV-XVIII, Madrid, Alianza, 1984, vol.I, pp.158-161. 
tino declive demográfico y económico de la ciudad, así como favorecida por la incapacidad de la administración a restringir aún más sus beneficios en años de mayor carestía, tal y como había procedido - véase el cuadro 5- durante la escasez de 1649. Este retroceso vino acompañado de una mayor demanda de cordero en las tablas de las carnicerías, de un precio más asequible. No obstante, a diferencia de otras localidades aragonesas y en especial de su capital, el suministro municipal de carne sólo proporcionó macho cabrío en años de extrema necesidad y alzas fuertes de precios de la carne como 1695 debido a la peor calidad de esta carne pese a su mayor baratura.

De acuerdo con la demanda local, tras recibir la vistreta del gestor saliente, el nuevo administrador efectuaba una primera estimación de las compras de ganado por realizar durante el año y practicaba las gestiones necesarias para su adquisición, supervisadas por los jurados. Con la segura participación de los ganados aragoneses y forasteros que habían subido desde el sur peninsular a los pastos de verano sitos en las sierras de Albarracín ${ }^{67}$, la celebración de la feria de San Miguel de Septiembre en la ciudad permitía estimar el valor de las reses en el mercado e incluso cerrar algunos tratos por parte del administrador saliente o entrante. Resultado de estos acuerdos son los 355 carneros comprendidos en la vistreta ${ }^{68}$ confiada al nuevo administrador del abasto en octubre de 1649. La crudeza del invierno, al determinar el volumen de pastos disponible para el ganado, marcaba la evolución de su precio durante el resto del año hasta cerrarse la administración en septiembre.

Frente a las ventas, mejor definidas en la contabilidad, las adquisiciones de ganado practicadas la administración de la carne en la segunda mitad del Seiscientos sólo pueden fijarse de forma aproximada —véase el cuadro 4- para las reses de menor consumo: corderos, ovejas y vacas. Concretado su número en el ejercicio de 1649, los restantes años contables sólo registran el beneficio neto derivado de su venta tras restar los costes de compra y mantenimiento sin mayores detalles. De acuerdo con lo constatado para 1649, se ha deducido que las compras de estas reses de menor demanda se limitaban a cubrir las necesidades anuales y se corresponderían a grandes rasgos con las ventas: las probables correcciones de-

67 Sobre el tema, CASTÁN, J.L., «La ganadería...», pp. 488-498; y FERNÁNDEZ OTAL, J.A., «La trashumancia en Aragón. Una síntesis histórica», en CASTÁN, J.L y SERRANO, C. (coords.), La trashumancia en la España mediterránea, Zaragoza, Centro de Estudios para la Despoblación y Desarrollo de Áreas Rurales, 2004, pp. 76-77.

68 AMA, Concejo, doc.146, libros de contabilidad de 1648-50. En el Noreste de Aragón y el valle del Ebro, incluida Zaragoza, la celebración de las ferias de Sariñena -del primer domingo, Ramos y Santa Cruz- resultaba esencial durante el período 1550-1650 para establecer la cotización de las reses en el mercado. Con frecuencia, en función de este valor, los municipios modificaban el precio oficial de venta de las carnes ofertadas en las carnicerías públicas. Véase SALAS J.A., La población..., pp. 75-77; OTERO, F., La Vila ..., p. 42; y MATEOS, J.A., «Municipio .... el abasto de carne...», pp. 191 y 195. Sobre la importancia de la estructura ferial y mercantil para el abastecimiento de los municipios castellanos durante el Quinientos, BernaRdos J.U., «El mercado de la carne en Castilla durante la Edad Moderna», en Actas del VIII Congreso de la Asociación Española de Historia Económica, Santiago de Compostela, Universidad, 2005, (cd-rom). 
rivadas del hurto, muerte y nacimiento de algún animal dentro del rebaño municipal o su inclusión ocasional en la vistreta entrañarían escasa importancia. A tono con el consumo en las tablas, frente a otros municipios aragoneses ${ }^{69}$, las adquisiciones practicadas por la administración admiten escasas reses cuya carne es de menor calidad —oveja, vaca — frente al predominio absoluto del carnero y una mayor presencia relativa del cordero.

Cuadro 4. Administración de la carne: compras de reses (1649-81) (en unidades)

\begin{tabular}{cccccc}
\hline Años & Carnero & Cordero & Oveja & Vaca & Buey \\
\hline 1649 & 960 & 180 & 28 & 6 & 2 \\
1650 & 888 & $(90)$ & 0 & $(6)$ & 0 \\
1667 & 840 & $(227)$ & 0 & $(10)$ & 0 \\
1668 & 735 & $(110)$ & 0 & $(11)$ & 0 \\
1681 & 735 & $(232)$ & 0 & 0 & 0 \\
\hline
\end{tabular}

Fuente: AMA, Concejo, doc.146.

( ) = Deducido a partir de las ventas.

Por fortuna, al ser las reses más demandadas, las adquisiciones de los carneros resultan más detalladas y su análisis revela notables informaciones sobre la gestión del abasto. De forma lógica, debido a la importante cabaña ganadera existente en la comarca circundante ${ }^{70}$, los principales abastecedores de reses destinadas a las carnicerías residen en Albarracín o localidades próximas tales como Royuela, Alobras, Tormón, Monterde, Pozondón y Alba. En parte favorecida al ser la demanda modesta, resulta significativa la adquisición de notables partidas por los gestores. Así, con frecuencia un solo ganadero proporcionó más de la mitad de las reses adquiridas ese año: Juan Bautista Sánchez aportará así 482 carneros en 1667, Gaspar Sepúlveda 550 en 1668 ó Mariana Cebrián 450 en 1681. Esta realidad refleja la gran influencia de los grandes propietarios del ganado en la Comunidad de Albarracín ${ }^{71}$. Ciudadanos e infanzones asentados en Teruel, Albarracín o villas importantes del entorno, estos ganaderos combinaron en diverso grado las actividades comerciales, el ejercicio de profesiones liberales o la percepción de rentas en dinero o especie. Seleccionados para ejercer los principales cargos en

${ }^{69}$ Como ejemplo, Otero, F., La Vila ..., p. 148.

70 Véase la nota 53.

71 Sobre el encuadramiento económico y social de los mayores propietarios de ganado en la Comunidad de Albarracín, CASTÁN, J.L. Pastores turolenses..., pp. 206-214. El poder económico de estos sectores se veía reforzado asimismo por su adscripción a agrupaciones ganaderas aragonesas sitas en el sur de Aragón como el ligallo de Teruel y la Mesta de Albarracín o incluso a la Mesta castellana. Sobre el marco institucional de la Mesta de Albarracín durante las Edades Media y Moderna, BERGES, J.M., «Para una historia de las instituciones ganaderas en Aragón. La mesta de Albarracín a través de sus Ordinaciones», en CASTÁN, J.L y SeRRAnO, C. (coords.), La trashumancia ..., pp. 265-363. 
el concejo y la Comunidad de Albarracín mediante la insaculación ${ }^{72}$, método usual en el reino aragonés, el control político ejercido por esta oligarquía se unió a su poder económico para consolidar una concepción del suministro público de carne muy favorable a sus intereses, defendida por esta elite social como un bien común para el conjunto de los ganaderos.

El cuidado de las reses adquiridas por el administrador del abasto municipal era confiado a pastores bajo la dirección de un mayoral ${ }^{73}$. Gracias a las dehesas destinadas a pasto vinculadas a las carnicerías ya descritas al tratar el sistema de arriendo, éstos sólo debían ejercer la trashumancia con parte de un rebaño. El limitado abasto asumido por la administración de la carne también contribuía a restringir su número ${ }^{74}$. En 1649 y 1681 este ganado trashumante comprendía 200 carneros. Sólo la gestión trienal de Luis Sánchez Santa Cruz en 1667-69 permitió aumentar de forma apreciable su número. En 1668 sumaba 352 carneros que, unidos a otras 128 reses pertenecientes al administrador, formaban un rebaño trashumante de medio millar de cabezas. En contraste, este mismo año 231 carneros vinculados al abasto -incluidos en la vistreta - más otros 132 carneros propiedad particular de Luis Sánchez pacieron en el cuarto de Aguas Amargas. En ambos casos, el administrador costeó de su bolsillo el pasto consumido por sus ganados, pero el salario del mayoral y pastores que cuidaban todo el rebaño corrió por entero por cuenta del concejo.

El modesto tamaño del ganado municipal parece primar la trashumancia «corta» y obviar aquellas rutas que comportaban distancias más considerables. Así, si el ganado no traspuso la Comunidad de Albarracín al pacer en Rubielos durante el invierno de 1650, fue conducido en 1649, 1667, 1668 y 1681 por estas fechas a «extremo» para pastar más allá de las fronteras de Aragón ${ }^{75}$. Pese a no detallarse

72 La implantación de este método en Aragón a fines de la Edad Media, en FALCón, M.I., «Origen y desarrollo del municipio medieval en el reino de Aragón», Estudis Balearics, 31, (1988), pp. 89-91. El grado de intervención monárquica en la elección de cargos municipales que permitía la insaculación en la Corona de Aragón durante la época foral moderna ha generado serias controversias cuyas líneas se recogen en JARQUE, E. y SALAS, J.A., «El poder municipal aragonés en tiempos de Felipe Il», en MARTíNEZ RuIz, E. (ed.), Madrid, Felipe Il y las ciudades de la Monarquía, Madrid, Actas, 2000, tomo I, pp. 199-215. Las disposiciones legales relativas a este sistema electivo en Albarracín durante los siglos XVI y XVII, en LATORRE, J.M. (coord.), Estudios..., vol. II, pp. 200-372.

73 Sobre las obligaciones de pastores, mayorales y rabadanes, CASTÁN, J.L. Pastores turolenses..., pp. 229-232.

${ }^{74}$ AMA, Concejo, doc.146, fol.5v, 15r, 20v-22r, 33r. Sobre la importancia de la trashumancia ganadera en Aragón durante las Edades Media y Moderna, consúltese FERNÁNDEZ OTAL, J.A., La Casa de Ganaderos de Zaragoza. Derecho y trashumancia a fines del siglo XV, Zaragoza, Institución Fernando el Católico, 1993, pp. 201-229 y «La trashumancia...», así como CASTÁN, J.L. Pastores turolenses..., pp. 307-396.

75 AMA, Concejo, doc.146, fol.13r., 14r-15v y 33r. Las áreas de invernada habituales para los ganados de la Comunidad de Teruel se hallaban en la llanura central valenciana (Jerica, Segorbe, Liria, Pedralaba, Chelva, Andilla, Buñol, Chiva, Tous, Enguera) o, ya en Alicante, en Villena y Orihuela. Junto a estas zonas, las reses procedentes de la sierra de Albarracín podían descender a Ciudad Real (valle de la Alcudia, Campo de Calatrava y Montiel) o el valle del Guadalquivir. Sobre el tema, ABAD, J.M., «La trashumancia en la Comunidad de aldeas de Teruel (siglos XIII-XV): una valoración documental», en CASTÁN, J.L. y SERRANo, C. (coords.), La trashumancia ..., p. 198 y CASTÁN, J.L., «La ganadería...», pp. 500-502. 
la ruta del ganado, el desplazamiento previo del mayoral para contratar los pastos necesarios ${ }^{76}$ identifican esta zona en 1667 con el reino de Valencia: la estancia del rebaño en Veguillas de la Sierra, sita en la frontera, permitió al administrador Luis Sánchez adquirir con reales valencianos 155 carneros a ganaderos aragoneses para abastecer a Albarracín. Por el contrario, el ganado se dirigió en 1681 hacia Castilla en pos de las rutas de la cañada conquense para, tras ser esquilado en Carnebuena, volver a la Comunidad de Albarracín a través de Orihuela del Tremedal. Dato significativo de los fuertes lazos comerciales que estos desplazamientos generaban, asentadas sobre las fuertes adquisiciones de ganado aragonés practicadas por el reino valenciano en la segunda mitad de la centuria ${ }^{77}$, la contabilidad de la administración recogía ya en 1695 como unidad de peso la libra carnicera de Valencia ${ }^{78}$.

Cuadro 5. Precio de compra y venta del carnero por la administración (1649-81) (en sueldos por unidades)

\begin{tabular}{cccccc}
\hline Concepto & 1649 & 1650 & 1667 & 1668 & 1681 \\
Compra & 46 & 46 & 41 & 44 & 36 \\
Venta & 51 & 59 & 50 & 55 & 45 \\
\hline
\end{tabular}

Fuente: AMA, Concejo, doc.146.

La ponderación de los criterios aplicados por la administración municipal durante estos años marcados por los mayores problemas de suministro tropieza con la imposibilidad de precisar los beneficios obtenidos por libra de carne. Los precios de venta se refieren por lo general al animal entero, sometido a engorde en dehesas y otras zonas de pasto ${ }^{79}$. Con todo, la comparación de los precios de compra y venta del carnero expuestos en el cuadro 5 revela que la administración extraía un rendimiento entre nueve y once sueldos por res que sólo era rebajado ante serias carestías, como sucede en 1649. Los ejercicios contables de 1667 y 1668 cifran el beneficio por cordero en dos sueldos y dos dineros, elevado hasta cuatro sueldos en 1681 debido a su mayor demanda por parte de la población. Las escasas vacas vendidas cada año rindieron en 1667 y 1668 treinta y dos sueldos de beneficio por unidad.

\footnotetext{
${ }^{76} \mathrm{Al}$ margen de dirigir el rebaño y elegir los itinerarios hacia las zonas de pasto, entre sus diversas obligaciones, el mayoral debía custodiar las franquicias de paso y albaranes de manifiesto del ganado, asumir el pago de los derechos reales y locales por el tránsito de las reses, así como sufragar los costes promovidos por su apacentamiento y esquileo. Véase la nota 73.

77 CASEY, J., El reino ..., pp. 81-82 y 98-99.

${ }_{78}$ AMA, Concejo, doc.146, fol. 35v. Los precios de compra de reses en Albarracín durante el siglo XVII pueden compararse con los recogidos para Barbastro en SALAS J.A., La población..., p. 91. Con todo, los datos relativos al coste de adquisición del carnero y cabrón expuestos en el cuadro 10 parecen haber sido intercambiados de forma errónea, según revelan los precios de venta por libra de una y otra res recogidos mediante el cuadro 11 en la página siguiente.
}

79 AMA, Concejo, doc.146. 
Gracias a este margen entre los precios de compra y venta, según revelan los cuadros 1 y 2, las ganancias de las carnicerías transferidas a la Mayordomía en 1667-69 mantienen niveles similares al período 1621-54 y se revelan nulas en 1681 al destinarse a mantener la vistreta. Pese a seguir una línea moderada de beneficios similar a la practicada bajo el arriendo que beneficia al consumidor, la administración de la carne se ve forzada - como el Pósito- a drenar sumas de dinero anuales a la caja central municipal para contener su déficit. Esta debilidad financiera imponía a ambas administraciones del trigo y la carne un menor margen de actuación ante las carestías al carecer de fondos para asumir pérdidas en estos años, tal y como revela el menor consumo en las carnicerías municipales por parte de la población al encarecerse el precio de venta de las distintas reses tras la mortandad del ganado padecida en 1695. Por tanto, el municipio tendrá una capacidad de intervención más limitada sobre las fluctuaciones de precios en un mercado ya muy condicionado por los tratos privados.

Fiel reflejo de esta menor capacidad de actuación sobre las transacciones, el municipio de Albarracín procederá a realizar durante la segunda mitad del siglo XVII tasaciones de diversos productos alimenticios en el mercado urbano con la intención de evitar alzas súbitas de precios ${ }^{80}$. Esta regulación tendrá especial énfasis sobre la caza y pesca obtenida en el entorno, objeto de demanda creciente por una población más empobrecida frente a la oferta más gravosa de la tienda y carnicería municipales, pese a la menor presión fiscal aplicada en Albarracín frente a muchos otros concejos. Ejemplo habitual en la época, el estatuto municipal aprobado en 1678 tasaba junto a los huevos y la fruta el precio de peces, mamíferos y aves tales como truchas, conejos, liebres, perdices, pichones, ánades, palomos y tordos. Como compensación a los proveedores locales, los pescadores y cazadores vecinos de la ciudad tenían permitido un pequeño beneficio adicional frente a los proveedores forasteros.

\section{CONCLUSIONES}

Pauta común de los poderes públicos en el Antiguo Régimen, la importancia concedida por el concejo de Albarracín a la política de abastos se revela evidente durante el Seiscientos. Si bien los gravámenes sobre la venta de vino obtienen una primacía excepcional entre los ingresos municipales, la gestión del Pósito y las carnicerías recogen la mayor importancia concedida por el poder público local a estos productos esenciales dada su fuerte incidencia en la dieta alimenticia de la población. Esta realidad hacía necesario que ambos organismos subordinados al con-

80 AMA, Concejo, doc.125. Según revela la documentación, las tasaciones de precios de productos y las disposiciones contra los revendedores que fomentan la especulación son recursos muy habituales — si bien poco efectivos - adoptados por los concejos aragoneses durante la segunda mitad del siglo XVII. Así, los bandos municipales conservados reflejan la adopción de esta misma estrategia en la capital del reino durante este período. Véase AMZ, Libros de Pregones n. ${ }^{\circ 15}$, fol.14v-16r, n. ${ }^{\circ} 16$, fol.176v-177v, n. ${ }^{\circ 17}$, fol. $80 r-82 r, 102 r-104 r$ y $222 r-223 v$. 
cejo no sólo tratasen de asegurar su suministro estable a un precio asequible, sino de desarrollar mecanismos para contener el alza de su precio en años de escasez. Con todo, la fuerte especialización ganadera de la zona introduce rasgos peculiares en la gestión del abasto público de carne. La capacidad concedida a la población para aprovisionarse en el mercado no sólo favorecía el consumo de los habitantes, sino que privilegiaba los intereses ganaderos, en especial de los mayores propietarios de reses que contaban con un notable peso político y económico local y comarcal.

El esquema general de la política de abastos se ve sacudido en el Aragón del Seiscientos conforme los concejos deban afrontar la reestructuración de la economía regional acuciados por la necesidad de ampliar los ingresos municipales ante su paulatino endeudamiento. Debido a su incidencia sobre los artículos alimenticios, la mayor presión fiscal municipal alteró el sustento de la demanda y la protección del consumidor afianzados durante el Quinientos y suscitó una fuerte oposición social. Promovió asimismo frecuentes conflictos entre sectores humildes, oligarquía municipal y estamentos privilegiados sobre la adopción de impuestos directos o indirectos, más comunes éstos últimos en las ciudades gracias al apoyo de las elites locales. Al incidir de forma desigual sobre la oferta de productos agrarios en los mercados locales, afectó a los distintos intereses de estos grupos sociales ligados a su comercialización. De acuerdo con estos objetivos, en especial en los núcleos urbanos, la redefinición de los impuestos municipales vino cada vez más condicionada en Aragón por el incremento tanto de la exportación de materias primas como de la competitividad del mercado agrario tras decaer la demanda interna y emerger una mayor especialización local y comarcal durante la segunda mitad de la centuria.

Frente a otros municipios aragoneses que optaron por aumentar el gravamen sobre la carne a lo largo del siglo XVII, el concejo de Albarracín mantuvo una baja presión fiscal más ligada a la política de abastos practicada en el Quinientos. Esta decisión, sorprendente dada la notable exportación de ganado del sur aragonés hacia el reino de Valencia, preservaba los intereses de las elites ganaderas en una zona carente de otras especializaciones agrarias al sustentar la demanda local de carne a costa de preservar el déficit de la hacienda municipal y acelerar su quiebra. Si bien este modesto nivel de tributación contó con un serio respaldo social al favorecer al consumidor en un período de declive económico, el concejo se vio más incapacitado por su endeudamiento para paliar ocasionales alzas de precios y carencias de suministro en la carne, sólo moderadas por la dedicación ganadera y contracción demográfica del entorno. Consecuencia última de esta debilidad financiera, el retroceso del control público frente a los intercambios privados aportó un mercado local más abierto y favorable a la progresiva extroversión y especialización agraria que presidió la reestructuración de la economía aragonesa durante el Seiscientos. 